\title{
Pharmaco-Immunomodulatory Therapy in COVID-19
}

\author{
John G. Rizk ${ }^{1} \mathbb{D} \cdot$ Kamyar Kalantar-Zadeh ${ }^{2,3,4} \cdot$ Mandeep R. Mehra $^{5} \cdot$ Carl J. Lavie $^{6} \cdot$ Youssef Rizk $^{7} \cdot$ Donald N. Forthal $^{8,9}$
}

Published online: 21 July 2020

(c) Springer Nature Switzerland AG 2020

\begin{abstract}
The severe acute respiratory syndrome coronavirus 2 associated coronavirus disease 2019 (COVID-19) illness is a syndrome of viral replication in concert with a host inflammatory response. The cytokine storm and viral evasion of cellular immune responses may play an equally important role in the pathogenesis, clinical manifestation, and outcomes of COVID-19. Systemic proinflammatory cytokines and biomarkers are elevated as the disease progresses towards its advanced stages, and correlate with worse chances of survival. Immune modulators have the potential to inhibit cytokines and treat the cytokine storm. A literature search using PubMed, Google Scholar, and ClinicalTrials.gov was conducted through 8 July 2020 using the search terms 'coronavirus', 'immunology', 'cytokine storm', 'immunomodulators', 'pharmacology', 'severe acute respiratory syndrome 2', 'SARS-CoV-2', and 'COVID-19'. Specific immune modulators include anti-cytokines such as interleukin (IL)-1 and IL-6 receptor antagonists (e.g. anakinra, tocilizumab, sarilumab, siltuximab), Janus kinase (JAK) inhibitors (e.g. baricitinib, ruxolitinib), anti-tumor necrosis factor- $\alpha$ (e.g. adalimumab, infliximab), granulocyte-macrophage colonystimulating factors (e.g. gimsilumab, lenzilumab, namilumab), and convalescent plasma, with promising to negative trials and other data. Non-specific immune modulators include human immunoglobulin, corticosteroids such as dexamethasone, interferons, statins, angiotensin pathway modulators, macrolides (e.g. azithromycin, clarithromycin), hydroxychloroquine and chloroquine, colchicine, and prostaglandin D2 modulators such as ramatroban. Dexamethasone $6 \mathrm{mg}$ once daily (either by mouth or by intravenous injection) for 10 days may result in a reduction in mortality in COVID-19 patients by one-third for patients on ventilators, and by one-fifth for those receiving oxygen. Research efforts should focus not only on the most relevant immunomodulatory strategies but also on the optimal timing of such interventions to maximize therapeutic outcomes. In this review, we discuss the potential role and safety of these agents in the management of severe COVID-19, and their impact on survival and clinical symptoms.
\end{abstract}

\section{Key Points}

COVID-19 is a syndrome of viral replication and a host inflammatory response.

Tackling the immune response may be as important as addressing viral replication.

Specific and non-specific immune modulators have the potential to inhibit cytokines and quell the cytokine storm.

John G. Rizk

john.rizk@lau.edu

Extended author information available on the last page of the article

\section{Introduction}

Although the pathogenesis of COVID-19, the result of infection with severe acute respiratory syndrome coronavirus 2 (SARS-CoV-2), is still not completely understood, a proposed four-stage classification system of escalating phases represents a useful construct for a structured approach to clinical phenotyping, choice of therapy, and clinical outcome $[1,2]$. Stage I (early infection) begins at the time of viral inoculation and establishment of infection. Patients may or may not manifest non-specific symptoms (i.e. malaise, fever, sore throat, dry cough), and treatment is often symptomatic. Stage II is characterized by hyperresponsiveness of the immune system. Patients develop viral pneumonia and possibly hypoxia, and markers of systemic inflammation are elevated. The third stage is characterized by a hypercoagulable state. Patients with hypoxia are likely to progress to stage $\mathrm{IV}$, the most severe stage, where multiorgan failure occurs. 
Most patients also develop lymphopenia and pneumonia with bilateral infiltrations on chest computed tomography (CT) scan [3-5]. Systemic proinflammatory cytokines and biomarkers such as interleukin (IL)-1, IL-2, IL-6, and IL-7, tumor necrosis factor (TNF)- $\alpha$, granulocyte-macrophage colony-stimulating factor (GM-CSF), macrophage inflammatory protein 1- $\alpha, \mathrm{C}$-reactive protein (CRP), ferritin, and D-dimer are significantly high in this stage $[4,6]$.

The presence of elevated proinflammatory cytokines in advanced stages of disease was also observed in prior epidemics, such as those caused by SARS-CoV and MERS$\mathrm{CoV}$, suggesting a cytokine release syndrome (CRS) or 'cytokine storm'-mediated immunopathology [7-9]. The cytokine dysregulation and influx of inflammatory myeloid cells can lead to lung infiltration and critical symptoms, including sepsis, shock, respiratory failure, acute respiratory distress syndrome (ARDS), multiorgan system dysfunction, and death [10]. Since lymphopenia is often observed in early and late stages of COVID-19 patients, the CRS may likely be mediated by leukocytes other than T cells [9]. The cytokine storm is thought to resemble secondary hemophagocytic lymph histiocytosis (sHLH) [11]. The macrophage activation syndrome (MAS)-like pulmonary immunopathology characteristic of COVID-19, above and beyond the direct endothelial damage from SARS-CoV-2, may explain the high degree of micro- and macrothrombotic findings in this patient population [12].

Cytokine storm, along with viral evasion of cellular immune responses, may play an equally important role in disease progression. Thus, tackling the immune response with immunomodulatory agents may be as important as addressing viral replication to prevent the progression to multiorgan dysfunction (Fig. 1). Herein, we discuss the role of specific and non-specific immunomodulating agents, including neutralizing monoclonal antibodies, corticosteroids, and other molecules in the management of severe COVID-19, and their impact on survival and clinical symptoms.

\section{Methods of Literature Review}

An English-language literature search was performed using PubMed and Google Scholar to identify relevant articles published through 8 July 2020 . Search terms included 'coronavirus', 'immunology', 'cytokine storm', 'immunomodulators', 'pharmacology', 'severe acute respiratory syndrome 2', 'SARS-CoV-2', and 'COVID-19'. The authors of this current review included case reports, case series, review articles, and randomized controlled trials. Ongoing and planned clinical trials were identified using the search term 'COVID$19^{\prime}$ on the ClinicalTrials.gov website.

\section{Immunomodulatory Agents}

Once a pathogen enters the body, it is addressed by two lines of defense: innate immunity and adaptive immunity (Fig. 2) [13]. Innate immunity encompasses a number of soluble and cell-based antimicrobial factors and is triggered very early after infection. Adaptive immunity, which consists of pathogen-specific antibody and T cells, develops later and contributes to both clearing of infection and immunity against subsequent infection. Innate and adaptive immunity work together to detect and eliminate pathogens. Immunomodulatory drugs can stimulate (immunostimulants), suppress (immunosuppressants) or modulate various aspects of the immune system, including both adaptive and innate immune systems [14]. Immunostimulators are often prescribed to enhance the immune response against infectious diseases, however, morbidity and mortality in severe COVID-19 is associated with hyperinflammation [15], and interfering with cytokine signaling using immunomodulatory strategies may significantly reduce hyperinflammation in these patients. The action of immunomodulators can be specific or nonspecific $[13,14]$.

\section{Specific Immune Modulators}

\subsection{Anti-cytokines}

\subsubsection{Interleukin (IL)-1 Receptor Antagonists}

Anakinra is a recombinant human IL-1 receptor antagonist indicated for rheumatoid arthritis (RA) and cryopyrinassociated periodic syndromes [16]. It works by inhibiting the proinflammatory cytokines IL- $1 \alpha$ and IL-1 $\beta$ [17]. In earlier studies, anakinra was shown to be effective in treating MAS, which presents as a fulminant cytokine storm [18]. This may suggest a role for anakinra in combating CRS symptoms in COVID-19 patients. Re-analysis of data from a phase III randomized controlled trial revealed that IL-1 receptor blockade with anakinra was associated with significant improvement in survival of patients with sepsis [19]. There are currently no published controlled clinical trials supporting the efficacy or safety of anakinra in treating COVID-19. In a small case-series of nine patients with moderate to severe COVID-19 pneumonia, the use of anakinra was well-tolerated and effective in improving clinical and biological markers [20]. In a different cohort study on patients with severe COVID-19, anakinra decreased both the need for invasive mechanical ventilation in the intensive care unit, and mortality [25\% 


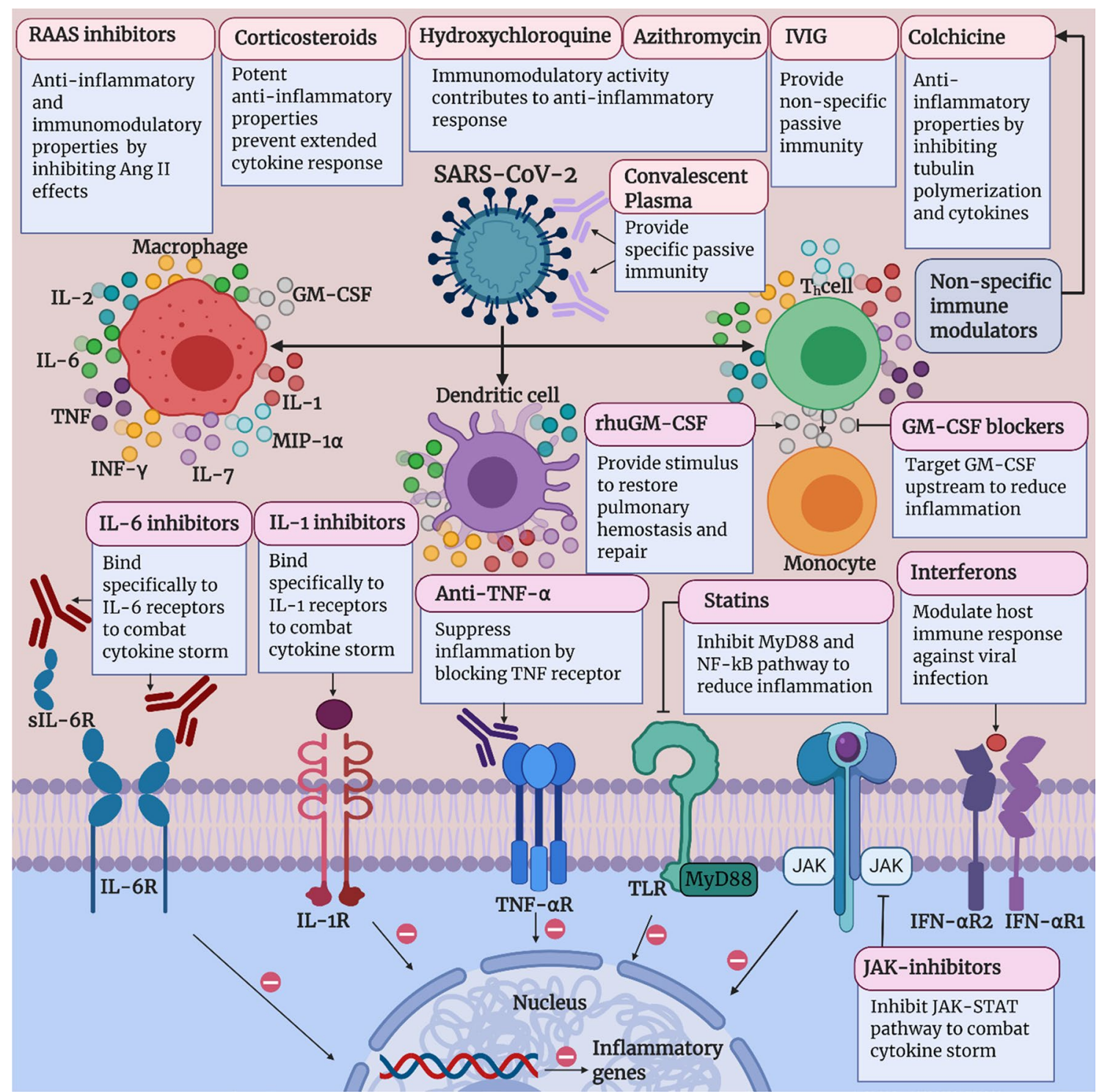

Fig. 1 Schematic representation of the immunomodulators' site of action. Hydroxychloroquine, azithromycin, statins, RAASi and their combinations have not been reliably shown to be of benefit in hospitalized patients with COVID-19, and therefore are represented here to define a potential pathophysiological target for therapy. This should not be seen as endorsement for use of such agents. The use of hydroxychloroquine and azithromycin in COVID-19 patients may be associated with harm. Whether such agents are beneficial in other stages of infection remains a matter of study. Created with biorender.com. Ang II angiotensin II, GM-CSF granulocyte-macrophage colony-

vs. $73 \%$, hazard ratio (HR) $0.22,95 \%$ confidence interval (CI) $0.11-0.41, p<0.0001]$ [21]. The efficacy of high-dose anakinra was evaluated in intensive care unit COVID-19 patients with a positive hemophagocytosis score (HScore) and diagnosed sHLH [22]. The mortality was lower than previous series of patients with sHLH in sepsis, although three patients died. The use of anakinra was associated stimulating factor, $I F N$ interferon, $I L$ interleukin, $I L-6 R$ interleukin-6 receptor, IVIG intravenous immunoglobulin, JAK Janus kinase, JAKSTAT Janus kinase-signal transducer and activator of transcription, $M I P-1 \alpha$ macrophage inflammatory protein $1-\alpha, M y D 88$ myeloid differentiation primary response $88, N F-\kappa B$ nuclear factor- $\kappa \mathrm{B}, R A A S$ renin-angiotensin-aldosterone system, rhuGM-CSF recombinant human granulocyte-macrophage colony-stimulating factor, $s I L-6 R$ soluble IL-6 receptor, TLR toll-like receptor, $T N F$ tumor necrosis factor reserve

with less need for vasopressors, significantly improved pulmonary function, and lower HScore.

A phase III, randomized, open-label, multicenter trial (NCT04324021) evaluating the efficacy and safety of anakinra and emapalumab, an anti-interferon (IFN)- $\gamma$ antibody, in the treatment of hyperinflammatory syndrome caused by the cytokine storm commenced on 2 


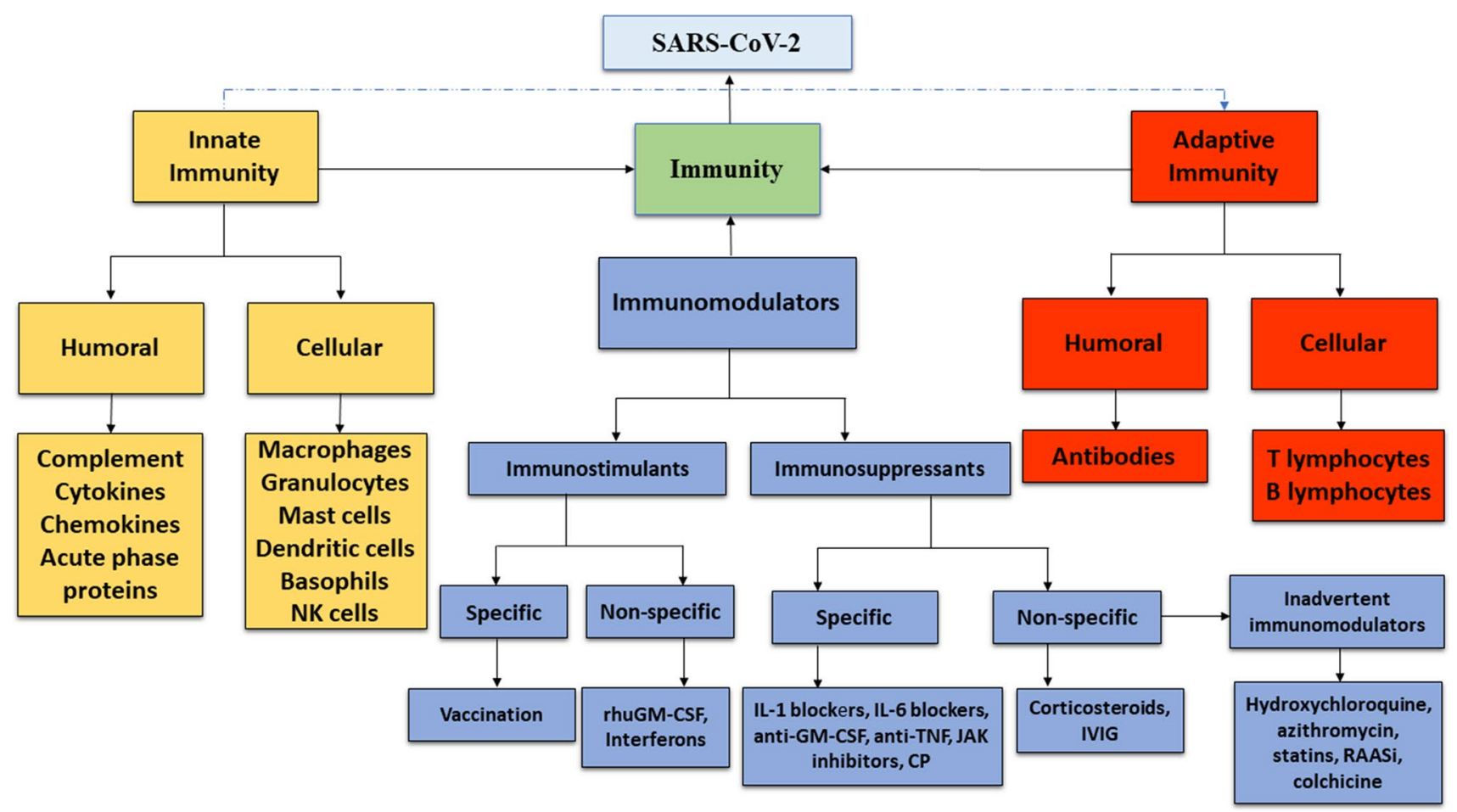

Fig. 2 The immune system is classically divided into innate and adaptive components. The innate immune system provides nonspecific resistance to pathogens, whereas adaptive immunity is characterized by antigen specificity and immunologic memory. Immunomodulators are drugs that either stimulate or suppress the immune system. The two immune systems, along with immunomodulators, work

April 2020 (NCT04324021). Although the subcutaneous formulation is the only US FDA-approved dosage form of anakinra [16], the dosage form being investigated in the ongoing trial is by intravenous infusion [20]. Other noncomparative, open-label studies underway in Greece (NCT04356366, NCT04339712) and Belgium (NCT04330638) are using the subcutaneous form.

\subsubsection{IL-6 Receptor Antagonists}

Abnormally high levels of IL-6 are an indicator of poor outcome in COVID-19 patients with pneumonia and ARDS [23]. Tocilizumab (Actemra $\left.{ }^{\circledR}\right)$ is a recombinant humanized anti-human IL-6 receptor monoclonal antibody that can specifically bind the membrane-bound IL-6 receptor (mIL6R) and soluble IL-6 receptor (sIL6R), thereby inhibiting signal transduction [24]. Tocilizumab is currently FDA-approved for the management of RA, giant cell arthritis, polyarticular juvenile idiopathic arthritis, and systemic juvenile idiopathic arthritis [24]. It is also approved for the management of chimeric antigen receptor (CAR) T-cell-induced CRS [24], making it a possible therapeutic option for CRS of severely together to prevent and control infection. $C P$ convalescent plasma, $I L$ interleukin, GM-CSF granulocyte-macrophage colony-stimulating factor, $I V I G$ intravenous immunoglobulin, JAK Janus kinase, $N K$ natural killer, RAASi renin-angiotensin-aldosterone system inhibitors, rhuGM-CSF recombinant human granulocyte-macrophage colonystimulating factor, $T N F$ tumor necrosis factor

ill COVID-19 patients who have extensive lung lesions and high IL-6 levels [25].

A single-arm Chinese investigation by $\mathrm{Xu}$ et al. included 21 severe or critical COVID-19 patients and showed that all patients who received tocilizumab demonstrated remarkable fever reduction within days following therapy, and a reduced need for supplemental oxygen was observed in 15 (75\%) patients [25]. The authors concluded that tocilizumab is an effective treatment in severely ill COVID-19 patients. Tocilizumab was administered as a single dose of $400 \mathrm{mg}$ by intravenous infusion, with only three (14.2\%) patients requiring an additional dose within $12 \mathrm{~h}$ of the first dose because of persistent fever. This dosing regimen was in agreement with the National Health Commission and State Administration of Traditional Chinese Medicine, which recommends a dose of $400 \mathrm{mg}(4-8 \mathrm{mg} / \mathrm{kg})$, and one additional administration after $12 \mathrm{~h}$ if ineffective, and a maximum single dose of $800 \mathrm{mg}$ [26]. Another Chinese retrospective, observational study by Luo et al. included 15 moderately to critically ill COVID-19 patients who received tocilizumab (80-600 mg per dose) in combination with methylprednisolone in 8 of the patients. Five patients received two or more doses of tocilizumab. Elevated CRP levels rapidly decreased in all 
patients following administration, and a gradual decrease in IL-6 levels was observed in patients who stabilized following tocilizumab administration. Three of the four critically ill patients who received a single dose died, suggesting that a repeated dose of tocilizumab may improve clinical outcomes [27]. Furthermore, a single-center, retrospective, observational Italian study of 20 renal transplant recipients with SARS-CoV-2 pneumonia included six patients who received tocilizumab. Three (50\%) of the patients experienced reduced oxygen requirements and two (33\%) showed improved radiologic findings following administration, whereas two $(33 \%)$ of the six tocilizumab-treated patients died [28]. In the TESEO study, a large, multicenter, retrospective cohort study of 544 patients, the use of intravenous or subcutaneous tocilizumab was associated with reduced risk of mechanical ventilation and death (adjusted HR 0.61, 95\% CI $0.40-0.92, p=0.020$ ) [27]. The primary outcome was a composite of death or progression to invasive mechanical ventilation. At day 14 after hospital admission, 22.6\% (95\% CI 16.2-29.0) of the patients who received tocilizumab had the primary outcome, compared with $36.5 \%$ (95\% CI 30.7-42.2) in those who received standard of care. Similar results were reported regardless of the route of tocilizumab administration.

There are multiple clinical trials planned or initiated using tocilizumab in COVID-19 patients in the US, China, and Europe. Interim results from CORIMUNO-TOCI (NCT04331808), an open-label, phase II, randomized clinical trial, showed that a significantly lower number of the patients in the tocilizumab arm achieved the primary outcome of need for ventilation, or death, at day 14. In China, a multicenter, randomized controlled trial evaluating the efficacy and safety of tocilizumab in 188 COVID-19 patients is ongoing [29]. The 94 patients in the experimental arm will receive conventional therapy with tocilizumab, while the remaining 94 patients in the control arm will receive conventional therapy alone. Another randomized, double-blind, placebo-controlled phase III trial is taking place at a global level in the US, Canada, UK, and Europe (NCT04320615). The study will evaluate the safety and efficacy of tocilizumab in combination with standard of care compared with placebo in approximately 330 patients.

Another IL-6 receptor antagonist that may potentially combat CRS and pulmonary symptoms in severely ill patients is sarilumab (Kefzara $\left.{ }^{\circledR}\right)$, which is indicated for the treatment of adult patients with moderately to severely active RA who have had an inadequate response or intolerance to one or more disease-modifying antirheumatic drugs [30]. Although there are no known published clinical trials supporting the use of sarilumab in COVID-19 patients, it may have a similar effect to tocilizumab on the inflammatory response in severely ill COVID-19 patients. A US-based, phase II/III, randomized, double-blind, placebo-controlled study evaluating the efficacy and safety of high- and lowdose intravenous sarilumab in hospitalized patients with severe COVID-19 is currently under way (NCT04315298). A preliminary analysis of the trial demonstrated that sarilumab was effective in critically ill (i.e. requiring mechanical ventilation or high-flow oxygenation, or required treatment in an intensive care unit) COVID-19 patients, but not in severely ill (i.e. did not require mechanical or high-flow oxygenation) patients. Accordingly, the phase III portion of the trial was narrowed to include only critically ill patients [31].

\subsubsection{Janus Kinase Inhibitors}

By inhibiting the Janus kinase (JAK)-signal transducer and activator of transcription (JAK-STAT) pathway, JAK inhibitors are hypothesized to play a role in the management of CRS in severely ill COVID-19 patients [32]. Ruxolitinib $\left(\mathrm{Jakaf}^{\circledR}\right)$ is a potent and selective oral inhibitor of both JAK1 and JAK2 protein kinases. It is indicated for intermediateor high-risk myelofibrosis, polycythemia vera, and steroidrefractory acute graft-versus-host disease [33]. Ruxolitinib interrupts signaling downstream of multiple proinflammatory cytokines, which constitute the cytokine storm and increased activation of the JAK-STAT pathway [32]. However, one concern about the use of these agents is the blockade of IFN $\alpha$, a cytokine critical in defense against viruses [34]. In addition, severe reactions after initiation of ruxolitinib were reported in two COVID-19 patients, and required drug discontinuation [35]. Both patients developed cutaneous reactions with purpuras and a progressive decrease in hematocrit values, and one patient also developed thrombocytopenia and a deep-tissue infection. These adverse events may be due to the concomitant use of ritonavir, a CYP3A4 inhibitor, leading to an increase in ruxolitinib plasma concentrations. Thus, the role and safety of this type of JAK inhibitor in the management of inflammatory cytokine storm caused by COVID-19 is questionable.

There are currently no published clinical trials to support the use of ruxolitinib or other JAK inhibitors in COVID19. Two ongoing phase III randomized clinical trials are evaluating the efficacy and safety of ruxolitinib plus standard of care, compared with standard-of-care therapy alone, in adult patients with COVID-19-associated cytokine storm (NCT04362137; RUXOCOVID), and in adults with COVID19-associated ARDS who require mechanical ventilation (NCT04377620; RUXCOVID-DEVENT). Additionally, open-label emergency Expanded Access Programs (EAP) for patients diagnosed with severe or very severe COVID-19 illness (NCT04337359) and patients with COVID-19-associated cytokine storm (NCT04355793) are underway.

Baricitinib (Olumiant ${ }^{\circledR}$ ) is another JAK1 and JAK2 inhibitor that is predicted to have a dual effect of reducing 
both viral entry and inflammation in COVID-19 patients [36]. Baricitinib might be preferred over other JAK-STAT signaling inhibitors, given its once-daily dosing and acceptable adverse effect profile [37]. Additionally, its low plasma protein binding properties and minimal interaction with CYP enzymes and drug transporters allows for well-tolerated concomitant use of baricitinib with the direct-acting antivirals (e.g. remdesivir) and other drugs [38]. However, the use of baricitinib is associated with increased thromboembolic events, which is concerning given that COVID19 patients are at risk of developing these events [39]. In an Italian open-label study of 12 patients with moderate COVID-19 pneumonia [40], baricitinib therapy combined with lopinavir/ritonavir was associated with significant improvement in clinical and laboratory parameters, and none of the patients required intensive care unit support, however, the study was limited by its small sample size and openlabel design. An open-label, multicenter, adaptive phase II/ III study to evaluate the safety and efficacy of baricitinib in hospitalized patients with COVID-19 has commenced (NCT04340232). Other clinical trials are evaluating baricitinib in combination with or without an antiviral agent for the treatment of COVID-19 (NCT04346147, NCT04320277, NCT04345289, NCT04321993). Notably, baricitinib is included as an arm in the National Institute of Allergy and Infectious Diseases' (NIAID) phase III adaptive COVID19 treatment trial [41]. Currently, the National Institutes of Health (NIH) COVID-19 Treatment Guidelines Panel recommends against the use of JAK inhibitors for the treatment of COVID19 except in the context of a clinical trial, in part because the broad immunosuppressive effect of JAK inhibitors outweighs the potential for benefit [42]. An NIHsponsored randomized, controlled trial (Adaptive COVID-19 Treatment Trial 2) combining the investigational antiviral remdesivir plus the anti-inflammatory drug baricitinib is currently underway and will investigate whether adding an anti-inflammatory agent to remdesivir can provide additional benefit for patients [43]. Patients will receive either the combination or remdesivir alone, the latter of which was the focus of the Adaptive COVID-19 Treatment Trial. This combination may be able to control the viral infection as well as reduce the immune system reaction.

\subsubsection{Anti-tumor Necrosis Factor-a}

TNF $\alpha$ plays a key role in almost all acute inflammatory reactions by inducing oxidative stress and inflammation. $\mathrm{TNF} \alpha$ is mainly produced by macrophages, although it can also be produced by monocytes, B cells, and other tissues. Activating TNF $\alpha$ also results in the production of IL-1 and IL-6 [44]. An excess amount of TNF is found in the plasma and tissues of patients with COVID-19 [45], which are reported to be produced by the high numbers of monocytes expressing TNF $\alpha$ [46]. It has been reported that the binding of SARS-CoV-2 to angiotensin-converting enzyme (ACE)-2 induces TNF $\alpha$-converting enzyme (TACE)-dependent shedding of the ACE2 ectodomain, which facilitates viral entry and causes tissue damage through TNF $\alpha$ production [47].

Anti-TNF $\alpha$ therapy, such as adalimumab or infliximab, is used in the management of several autoimmune inflammatory diseases such as RA, inflammatory bowel disease, and ankylosing spondylitis [48]. Experimental studies suggest a potential rationale for use of anti-TNF therapy in viral pneumonia [46]. It has been proposed that a single infusion of anti-TNF $\alpha$ antibody can significantly reduce the amount of TNF in the blood [49], suggesting a possible anti-inflammatory benefit in COVID-19. Besides its classical effect on TNF $\alpha$ inhibition, anti-TNF $\alpha$ may also induce the downregulation of ACE2 expression and shedding [47, 50]. However, there is also concern that anti-TNF $\alpha$ therapy might increase the risk of bacterial or fungal superinfections [49].

Their effectiveness, wide availability, various dosage forms, and safety profile make anti-TNF $\alpha$ antibodies, particularly adalimumab, a promising therapeutic option for mitigating the inflammatory stage in COVID-19. It may be reasonable to initiate anti-TNF $\alpha$ therapy as early as possible [49], as delayed treatment may limit the effectiveness of these agents. The potential role of anti-TNF $\alpha$ therapy warrants consideration and should be investigated as a potential therapy to prevent progression to more advanced stages. A Chinese study evaluating adalimumab in COVID-19 infection is underway (ChiCTR2000030089). A prospective, single center, phase II trial evaluating the efficacy of infliximab or infliximab-abda in hospitalized adult patients with severe or critical COVID-19 has also commenced (NCT04425538).

\subsection{Granulocyte-Macrophage Colony-Stimulating Factor}

GM-CSF is a pleiotropic growth factor and proinflammatory cytokine that is released from alveolar epithelial cells and has been shown to drive pulmonary host defense function against pathogens, including the influenza virus [51]. Besides their role in inducing proliferation and differentiation of macrophages and dendritic cells [52], GM-CSF stimulates epithelial repair, including epithelial proliferation and barrier restoration, through direct interaction with the alveolar epithelial cells, thereby providing a lung-protective effect [51]. In patients with ARDS, elevated GM-CSF levels in the bronchoalveolar lavage fluid (BALF) are associated with antiapoptotic effects and improved epithelial barrier integrity and survival $[53,54]$. Studies have shown that GM-CSF can have a dual role as a proinflammatory and regulatory cytokine, depending on the dose and presence of other relevant cytokines [55]. The proinflammatory signal of GM-CSF can induce macrophages to elicit an immune 
response via a positive feedback mechanism that can ultimately result in tissue damage. Recent studies on COVID-19 patients show that increased levels of GM-CSF contribute to the immunopathology of ARDS $[4,56]$.

Given their effects in driving immune functions, GMCSFs may confer benefit to COVID-19 patients by providing the stimulus to restore pulmonary hemostasis and repair [57]. Previous studies have shown that a low-dose of intravenous GM-CSF in severely septic adult patients with respiratory dysfunction improves oxygenation and gas exchange [58], although it failed to improve survival and ventilation parameters in adult patients with acute lung injury in another trial [57]. There is evidence to suggest that the application of GM-CSF by the inhalation route may represent an effective strategy for pneumonia-associated ARDS [52]. Sargramostim $\left(\right.$ Leukine $^{\circledR}$ ), the only FDA-approved GM-CSF, is a yeast-derived recombinant humanized GM-CSF (rhuGMCSF) that is currently being investigated as an adjuvant therapy for the management of COVID-19 associated with acute hypoxic respiratory failure and ARDS (NCT04326920). Patients will be randomized to receive nebulized sargramostim $125 \mu \mathrm{g}$ twice daily for 5 days in addition to standard of care, or standard-of-care treatment alone. Patients in the experimental arm who progress to ARDS requiring initiation of invasive mechanical ventilation within the 5-day period will be switched to intravenous sargramostim $125 \mu \mathrm{g} / \mathrm{m}^{2}$ body surface area until the 5-day period is complete. Since high levels of GM-CSF in the alveoli should be achieved for virus clearance and acute lung injury, as well as ARDS treatment [52], it is important that GM-CSF be investigated via the inhaled route [51].

On the other hand, GM-CSF levels are upregulated in the serum of COVID-19 patients with a cytokine storm [59, 60]. Since GM-CSF functions upstream of other proinflammatory cytokines and chemokines, GM-CSF-targeted immunomodulation may be a viable therapy for this stage of the disease. One potential agent is gimsilumab, a clinical stage, fully human monoclonal antibody targeting GM-CSF. A randomized, double-blind, placebo-controlled, multicenter pivotal trial evaluating the role of intravenous gimsilumab in the prevention and treatment of ARDS and mortality in COVID19 is underway (NCT04351243). A single-arm, open-label pilot study will study the role of TJM2, a monoclonal antibody capable of neutralizing GM-CSF, in decreasing cytokine levels in severe SARS-CoV-2 patients [61]. Other anti-GM-CSF agents, including lenzilumab (NCT04351152) and namilumab [62], are also being evaluated.

\subsection{Convalescent Plasma}

There is evidence to suggest that convalescent plasma transfusion from patients who have recovered from the infection with a high neutralizing antibody titer (NAT) may provide short-term passive immunity that could be beneficial in the prevention of infection or as a treatment strategy for patients with COVID-19 [63-68]. Convalescent plasma has previously been used to improve the survival rate of patients with SARS, Ebola, H1N1, and MERS, all of which showed variable outcomes $[66,69,70]$.

In a study of 93 patients with severe H1N1 2009 infection requiring intensive care, 20 (21.5\%) of whom received convalescent plasma therapy, the use of plasma was associated with a reduction in the viral load on days 3,5 , and 7 $(p<0.05)$, cytokine and chemokine levels $(p<0.05)$, and mortality ( $20 \%$ vs. $54.8 \%$; $p=0.011)$ [71]. A systematic review by Mair-Jenkins et al. reported a statistically significant $75 \%$ reduction in the odds of mortality in SARS and severe influenza patients who received convalescent plasma [72]. SARS patients who received convalescent plasma within 14 days after the onset of symptoms manifested better outcomes than those who received treatment later in the disease course [63, 64, 69, 72]. Serious adverse events or complications were not reported, however, the studies were of low quality and mainly uncontrolled.

Shen et al. reported the first study of five critically ill COVID-19 patients with ARDS requiring mechanical ventilation who received two consecutive convalescent plasma transfusions containing high-titer neutralizing antibodies (NAT of 80-480) in conjunction with continued methylprednisolone and antiviral treatment [73]. Before transfusion, patients displayed continuously high viral load despite antiviral treatment for at least 10 days. Plasma transfusion was administered 10-22 days after admission. All patients eventually improved clinically: in four patients, ARDS resolved 12 days following transfusion, three patients were weaned from mechanical ventilation within 2 weeks, the body temperature of four patients normalized within 3 days, Sequential Organ Failure Assessment (SOFA) score decreased, $\mathrm{P}_{\mathrm{AO} 2} / \mathrm{F}_{\mathrm{IO} 2}$ increased within 12 days, viral loads decreased and became negative within 12 days after transfusion, and SARS-CoV-2-specific enzyme-linked immunosorbent assay (ELISA) and NATs increased. In another pilot study [74], 10 adults with severe COVID-19 received a single transfusion of COVID-19 convalescent plasma (NAT of 1:640 or greater) in addition to standard care, all patients received monotherapy or combination antiviral therapy, and six patients also received methylprednisolone. The mean time from onset of illness to transfusion was 16.5 days (interquartile range [IQR] 11.0-19.3). COVID-19 symptoms, such as fever, cough, shortness of breath, and chest pain improved in all patients within 1-3 days following transfusion. Patients showed variable degrees of improvement on chest $\mathrm{CT}$, where those transfused before 14 days post onset of illness showed better improvement. NAT increased in five patients after the transfusion, but remained the same in four patients. Reverse transcription polymerase chain 
reaction (RT-PCR) tests for SARS-CoV-2 RNA were positive in seven patients before transfusion. After transfusion, SARS-CoV-2 RNA was undetectable in three patients on day 2 , three patients on day 3 , and one patient on day 6 . More recently, an FDA-initiated, national, multicenter, open-label EAP study (NCT04338360) in 5000 hospitalized adults who were at high risk of progressing to severe or life-threatening COVID-19, showed that transfusion of ABO-compatible COVID-19 convalescent plasma (200-500 mL) was welltolerated [75]. Fewer than $1 \%$ of patients manifested major adverse events such as transfusion-associated circulatory overload, transfusion-related acute lung injury (TRALI), and severe allergic transfusion reaction, and only two of these events were clinically judged as certainly associated with the transfusion.

On the other hand, a Chinese open-label, multicenter, randomized controlled study evaluating the efficacy and safety of convalescent plasma therapy on 103 COVID-19 patients with severe or life-threatening disease found no significant difference in time to clinical improvement within 28 days, mortality, or time to hospital discharge [76]. Clinical improvement within 28 days was only observed in the subgroup of patients with severe COVID-19 disease (HR $2.15,95 \%$ CI 1.07-4.32, $p=0.03)$. However, most patients received convalescent plasma treatment at least 14 days after symptom onset, further suggesting that convalescent plasma therapy should be initiated earlier. Major adverse events were not observed, except for two patients who experienced adverse events within hours following transfusion that were managed with supportive care.

\section{Non-specific Immune Modulators}

\subsection{Human Immunoglobulin}

Intravenous immunoglobulin (IVIG) contains immunoglobulin $\mathrm{G}$ of all subclasses obtained from pooled human plasma [77]. IVIG has been used to provide immunity to viral infections [78], including SARS, although the benefits of the treatment were inconclusive and some cases of thromboembolic complications were reported [79, 80]. IVIG is different from hyperimmune globulin from convalescent plasma, wherein the plasma is prepared from the plasma of donors with high antibody titers to specific pathogens [81]. The mechanisms of action of IVIG are complex, and several mechanisms might account for its therapeutic benefit [82]. IVIG can inhibit the activation and functions of various innate immune cells, and can neutralize activated complement components. It also impacts the adaptive immune system by modulating B-cell functions and plasma cells, regulating regulatory $\mathrm{T}$ cells and effector $\mathrm{T}$ cells such as $\mathrm{T}$-helper (Th) 1 and Th17 subsets, and inhibiting inflammatory cytokines. It has also been proposed that IVIG can exert anti-inflammatory action by saturating Fc $\gamma$ receptor binding, and binding to antiviral antibodies and proinflammatory cytokines [81].

Cao et al. reported on three patients with severe COVID19 who received high-dose IVIG at a dose of $0.3-0.5 \mathrm{~g} /$ $\mathrm{kg} /$ day for 5 days [83]. All patients clinically improved shortly after the administration, normal body temperature was achieved in 1-2 days and respiratory rate improved in $3-5$ days. These results are in line with a retrospective study of 58 severe to critically ill COVID-19 patients [84]. The study reported a statistically significant difference in 28-day mortality between patients who received IVIG adjuvant therapy for COVID-19 pneumonia within $48 \mathrm{~h}$ of admission compared with those who received IVIG after $48 \mathrm{~h}$ ( $23.3 \%$ vs. $57.1 \%, p=0.009)$. Thus, as with convalescent plasma, earlier initiation of therapy is encouraged. In spite of this, a different retrospective study of 325 severe or critical COVID-19 patients reported no difference in 28-day or 60-day mortality between patients who were treated with IVIG and those who were not (https://www.medrxiv.org/ content/10.1101/2020.04.11.20061739v2.full.pdf).

Several randomized controlled trials evaluating the efficacy of IVIG therapy in severe COVID-19 are underway (NCT04350580, NCT04381858, NCT04261426). Both the NIH COVID-19 Treatment Guidelines Panel and the Surviving Sepsis Campaign COVID19 subcommittee do not recommend the use of commercially available IVIG (i.e. non-SARS-CoV-2-specific IVIG) for the treatment of COVID-19, in part because the current IVIG preparations are not likely to contain SARS-CoV-2 antibodies [42, 85]. IVIG benefits observed from current products can be due to anti-inflammatory mechanisms. It is likely that newly manufactured commercial IVIG preparations may contain antibodies against COVID-19, although this would depend on donor demographics.

\subsection{Corticosteroids}

Corticosteroids have potent anti-inflammatory and antifibrotic properties, which theoretically could have a role in suppressing lung inflammation, particularly in the advanced stages of the disease [86]. The debate regarding the use of corticosteroids in COVID-19 patients is far from conclusive. Low doses of corticosteroids downregulate proinflammatory cytokine transcription, consequently preventing an extended cytokine response and accelerating the resolution of pulmonary and systemic inflammation in pneumonia [87]. Additionally, corticosteroids may help improve the dysregulated immune response caused by sepsis [88], a possible complication of COVID-19, and can increase blood pressure in hypotensive patients [89]. However, the use of corticosteroids can inhibit immune response, reduce 
pathogen clearance, and provoke viral replication [86, 90]. Thus, it might be reasonable to use corticosteroids in severe cases of COVID-19 with ARDS, providing that a low dose $(\leq 0.5-1 \mathrm{mg} / \mathrm{kg} /$ day of methylprednisolone or equivalent) and short duration ( $\leq 7$ days) are used [26, 85, 91, 92].

Earlier studies have shown that corticosteroid use in patients with SARS, MERS, and influenza was associated with no survival benefit and possible harm. Patients with SARS receiving corticosteroids reported adverse events such as avascular necrosis, psychosis, diabetes, and delayed viral clearance [78]. Influenza patients manifest a higher risk of mortality and secondary infections with corticosteroids [93]. In MERS patients, corticosteroids delayed lower respiratory tract clearance of MERS-CoV, although no effect on mortality was reported [94]. Clinicians should balance the potential adverse effects of corticosteroids with the potential effects of prolonged coronavirus shedding.

Currently, the World Health Organization (WHO) and Centers for Disease Control and Prevention (CDC) do not recommend the routine use of systemic corticosteroids for treatment of viral pneumonia unless indicated for another reason, such as asthma or chronic obstructive pulmonary disease exacerbation, or refractory septic shock $[95,96]$. The Surviving Sepsis Campaign COVID-19 subcommittee recommends against the routine use of systemic corticosteroids in mechanically ventilated adults with COVID19 and respiratory failure (without ARDS), although this is a weak and poorly substantiated recommendation [85]. However, these recommendations may be amended based on preliminary results from the RECOVERY trial, which showed that dexamethasone reduces mortality among COVID-19 patients with severe respiratory complications [97]. Low-dose dexamethasone (6 mg once daily, orally or intravenously) for 10 days reduced deaths by one-third in patients on mechanical ventilation [rate ratio (RR) $0.65,95 \%$ CI $0.48-0.88 ; p=0.0003]$ and by one-fifth in patients receiving oxygen only (RR $0.80,95 \%$ CI $0.67-0.96 ; p=0.0021$ ); however, no benefit was reported in patients with milder symptoms (i.e. not requiring respiratory support). Prior to these findings, a multicenter, randomized controlled trial (DEXA-ARDS) studied the effects of intravenous dexamethasone at a dose of $20 \mathrm{mg}$ once daily on days $1-5$, followed by $10 \mathrm{mg}$ once daily on days 6-10 in non-COVID-19 patients with moderate-to-severe ARDS receiving lung-protective mechanical ventilation [98]. Compared with those receiving conventional treatment, the addition of dexamethasone to the therapy regimen lead to a reduction in mechanical ventilation duration (between-group difference of 4.8 days, 95\% CI 2.57-7.03, $p<0.0001)$, and in overall mortality at day 60 (between-group difference $-15.3 \%, 95 \%$ CI -25.9 to $-4.9 ; p=0.0047)$. Accordingly, a multicenter, randomized, controlled, open-label trial (DEXA-COVID19) involving mechanically ventilated adult patients with
ARDS with confirmed COVID-19 infection has commenced (NCT04325061). Compared with methylprednisolone, dexamethasone has less mineralocorticoid activity and is less likely to cause sodium and fluid retention, a concern in this patient population [90].

The use of methylprednisolone in severe COVID-19 patients was evaluated in several retrospective, observational studies. Wang et al. showed that in 46 patients with confirmed severe COVID-19 pneumonia that progressed to acute respiratory failure, the use of methylprednisolone $1-2 \mathrm{mg} / \mathrm{kg}$ daily intravenously for 5-7 days in 26 patients was associated with a shorter average number of days to fever resolution $(2.06 \pm 0.28$ vs. $5.29 \pm 0.70 ; p=0.010)$, faster improvement of $\mathrm{SpO}_{2}$, and lower number of days on supplemental oxygen therapy [8.2 days (IQR 7.0-10.3) vs. 13.5 days (IQR 10.3-16); $p<0.001$ ] [99]. Death occurred in three patients during hospitalization, two of whom received methylprednisolone. Wu et al. showed that treatment with methylprednisolone decreased the risk of death (HR 0.38, 95\% CI 0.20-0.72, $p=0.003$ ) among patients with ARDS [6]. Higher doses of methylprednisolone have been recommended for managing the cytokine storm: methylprednisolone $60-125 \mathrm{mg}$ every $6 \mathrm{~h}$ for up to 3 days, followed by dose tapering when CRP levels begin to decline [90].

\subsection{Interferons}

IFNs are cytokines that play a key factor in reducing viral multiplication and modulating host immune response against viral infection [100]. They consist of the ubiquitous $\alpha$ and $\beta$ subtypes. IFNs are released by plasmacytoid dendritic cells during a viral infection [100]. IFN treatment has been studied against MERS-CoV and SARS-CoV [78]. Due to their nonspecific antiviral effects, IFNs are mainly tested in combination with other agents, such lopinavir/ritonavir, ribavirin, remdesivir, corticosteroids, or IFN $\gamma$ [100]. When IFNs bind to their receptors, they activate IFN-stimulated genes, which play an important role in inflammation, signaling, and immunomodulation [100]. IFNs also sensitize human cells to viral proteins to prevent viral fusion or egress [100]. In vitro studies suggest that SARS-CoV-2 may be more sensitive to IFN than other coronaviruses [101]. While INFs were shown to be efficient in in vitro and animal models, they did not demonstrate a beneficial effect in patients with SARS [102].

A 2003 open-label, uncontrolled study of 22 SARS patients, 9 of whom received corticosteroids in combination with INF alfacon-1, showed that patients who received this combination were less likely to be admitted to the intensive care unit ( $11.1 \%$ vs. $38.5 \%$ ), had a shorter time to $50 \%$ resolution of lung radiographic abnormalities (4 days vs. 9 days; $p=0.001$ ), and had better oxygen saturation (10 days vs. 16 days; $p=0.02$ ) compared with SARS patients who 
received corticosteroids alone [103]. Another retrospective cohort study of 44 patients investigated the use of ribavirin and INF $\alpha$-2a compared with ribavirin alone for the management of severe MERS. The study reported both a 14-day and 28-day survival advantage in favor of the combination (70\% vs. $29 \%, p=0.004$ at 14 days; $30 \%$ vs. $17 \%, p=0.054$ at 28 days) [104].

INFs are being investigated for use in nebulized form (IFN $\alpha-2 b)$ or as subcutaneous injections (INF $\beta-1 b$ ) for the management of COVID-19 (NCT04293887, NCT04350281). Clinical trials evaluating subcutaneous peginterferon lambda-1a for treatment (e.g. NCT04354259, NCT04388709) and postexposure prophylaxis (e.g. NCT04344600) of SARS-CoV-2 infection are also underway. A multicenter, randomized, prospective study on pediatric patients with respiratory syncytial virus investigated the use of nebulized INF $\alpha-1 \mathrm{~b}$ compared with the subcutaneous injection. The study revealed that the nebulized form has a faster onset of action, a direct action on the mucosal epithelial cells in the lungs, less systemic adverse effects, and is less invasive to the pediatric population compared with the subcutaneous form [105].

Recently, a multicenter, prospective, open-label, randomized, phase II trial included 127 adult patients with COVID-19 who received triple antiviral therapy of lopinavir/ritonavir, ribavirin, and nebulized IFN $\beta-1 b$ [106]. The use of early triple antiviral therapy was well-tolerated and superior to lopinavir/ritonavir alone in alleviating symptoms [defined as a national early warning score 2 (NEWS2) of 0 (4 days vs. 8 days; HR 3.92, 95\% CI 1.66-9.23; $p<0.0001$ ) and a SOFA score of 0 (3.0 days vs. 8.0 days; HR 1.89, 95\% CI $1.03-3.49 ; p=0.041)]$ and in shortening hospital stay (9.0 days vs. 14.5 days; HR $2.72,95 \%$ CI $1.2-6.13$; $p=0.016)$. In addition, the combination group had a significantly shorter median time from treatment initiation to negative nasopharyngeal swab ( 7 days vs. 12 days; HR 4.37, 95\% CI 1.86-10.24; $p=0.0010$ ), suggesting that the triple antiviral therapy could shorten the duration of viral shedding. Additionally, in a retrospective study of 77 hospitalized adults with moderate COVID-19 disease who received aerosolized IFN $\alpha$-2b (5 million units twice daily; $n=7$ ), umifenovir $(n=24)$, or both drugs $(n=46)$, the time from symptom onset to negative RT-PCR result in the throat swab was shorter in the arm receiving IFN $\alpha-2 b$ alone or in combination with umifenovir compared with those receiving umifenovir alone [107], however, the study was limited by its small sample size, nonrandomized design, and dissimilar patient demographics and characteristics.

\section{Miscellaneous/Inadvertent Immunomodulators}

\subsection{Statins}

Besides their role in cardiovascular risk reduction, statins are reported to play a role in protecting the innate immune response to COVID-19 [108]. The Massachusetts General Hospital guide for critically ill patients with COVID-19 advocates for the consideration of using statins, particularly in patients who are admitted to the intensive care unit [109]. Since inflammation plays an important role in more severe manifestations of COVID-19, the anti-inflammatory properties of statins might potentially be useful [110]. In experimental studies, statins have been shown to decrease inflammation [111] and blunt the production of proinflammatory cytokines, including CRP and IL-6 [111]. In addition, statins have direct beneficial effects that lead to decreased pulmonary vascular injury and ultimately decreased lung injury [111]. However, these findings were reported in in vitro and animal studies that are generally performed in response to bacterial infections, and these effects have not been validated in humans.

Infection with SARS-CoV results in increased induction of the myeloid differentiation primary response 88 (MyD88) gene, which activates the nuclear factor (NF)-kB pathway and induces inflammation [112]. Consequently, IFN-I is also reduced [113]. In mice, inhibition of NF-kB is associated with a reduction in inflammation and lung pathology and increased mouse survival after SARS-CoV infection [113]. Overexpression or underexpression of the MyD888 gene can increase the vulnerability to infection and mortality from SARS-like coronaviruses [114, 115]. While statins do inhibit the MyD88 pathway, they tend to preserve MyD88 levels during hypoxia and under stress, which may confer a protective effect in COVID-19 patients [116].

In a multihospital retrospective cohort study of 2746 patients describing the prevalence of myocardial injury in COVID-19 patients, Lala et al. reported that statins have a protective effect and were associated with improved survival (HR 0.57, 95\% CI 0.47-0.69) [117]. While statins have a firmly established benefit in the context of myocardial injury, clinical trials demonstrating whether statins confer an antiinflammatory effect or allow for improvement of endothelial dysfunction in COVID-19 are warranted. The beneficial effects of statins on COVID-19-related clinical symptoms were also described in a different retrospective multicenter cohort study [118]. The study reported a statistically significant association between statin use and asymptomatic status, defined as having no disease symptoms in the entire study duration while testing positive on PCR (unadjusted odds 
ratio $2.91,95 \%$ CI $1.27-6.71, p=0.011)$. Serious COVID19 symptoms were observed in 19\% (6/31) of patients taking a statin compared with 25\% (31/123) in those not taking a statin, although this finding was not statistically significant. Although not statistically significant, six of eight patients (75\%) taking an ACE inhibitor (ACEi) or angiotensin II receptor blocker (ARB) and statin concomitantly remained asymptomatic throughout the duration of the study, which may suggest that this combination may have an additive beneficial effect on symptoms and clinical outcomes. Patients with confirmed or suspected COVID-19 who have an appropriate indication for statin use should continue or initiate therapy. However, if a COVID-19 patient does not have a cardiovascular indication for a statin, it might not be reasonable to commence therapy unless it is part of a clinical trial.

\subsection{Renin-Angiotensin-Aldosterone System Inhibitors}

The renin-angiotensin-aldosterone system (RAAS) inhibitors, ACEi and ARB, confer potent dual effects, not only as cardiovascular protective therapies but also as antiinflammatory and immunomodulatory agents [119]. ACE2, the enzyme that converts angiotensin (Ang) I to Ang II, is expressed near the surface of human epithelial cells throughout the body, including the lungs [120]. ACE2 receptors are the human cell entry points for SARS-CoV-2 [120]. It was shown with SAR-CoV-1 that binding to ACE2 led to its downregulation and increased Ang II [120]. There is a theoretical risk that ACEIs and ARBs can increase SARSCoV-2 attachment by upregulating ACE2 [121], although this was not substantiated by any human data and is an urgent research priority.

There is opposing evidence that being placed on an RAAS inhibitor could reduce the severity of lung injury in some viral pneumonias [122]. ACEi and ARB block the downstream effects of Ang II. Notably, Ang II is known to foster inflammation, oxidation, vasoconstriction, and fibrosis [123]. Therefore, a pharmacological agent that inhibits the production of Ang II could be beneficial for preventing lung injury and improving systemic health. Additionally, ACEi and ARB have a secondary effect of increasing ACE2 expression. ACE2 catalyzes the conversion of Ang II to Ang 1-7, which binds to the Mas receptor (MasR), leading to vasodilation and anti-inflammatory, antioxidant and antiapoptotic effects [123].

A large, observational study analyzed the electronic health records of 12,594 patients in New York City who were tested for SARS-CoV-2 [124], 5894 of these patients tested positive for the virus. A history of hypertension was described in 4357 patients (34.6\%), of whom 2573 (59.1\%) had a positive test, and 634 (24.6\%) COVID-19-positive patients had severe illness. There was no difference in the likelihood of a positive test for SARS-CoV-2 between patients treated with an antihypertensive agent, including an ACEi or ARB, and matched untreated patients. There was also no difference in the likelihood of severe COVID-19 disease between patients treated with an antihypertensive agent and untreated patients. In line with these findings, a large Italian population-based case-control study of 6272 patients with confirmed SAR-CoV-2 infection revealed that there is no evidence that the use an ACEi or ARB affected the risk of COVID-19, severity of the clinical manifestations, or the course of infection [125]. While the use of an ACEi or ARB was more commonly used in patients with COVID-19 than in controls, this was due to the higher prevalence of cardiovascular disease in these patients. Both of these large studies demonstrated that the use of an ACEi and ARB is not associated with an increased risk of infection with SARS-CoV-2. Thus, these agents should not be discontinued, unless the drugs cannot be tolerated due to hemodynamic instability [126]. If a COVID-19 patient has an indication for these agents, therapy should be started or continued.

\subsection{Macrolides}

Macrolides, such as azithromycin and clarithromycin, are antibiotics with immunomodulatory and anti-inflammatory effects [127-134]. It was demonstrated that macrolides downregulate proinflammatory cytokines, although the exact mechanisms of these effects are not fully illuminated. Azithromycin has been used as an adjunctive therapy to provide antibacterial and potential immunomodulatory effects in the treatment of viral respiratory tract infections, including influenza [133, 135], and other respiratory conditions, such as ARDS [128, 129]. In a retrospective cohort study by Kawamura et al., patients with moderate or severe ARDS who received adjunctive azithromycin manifested a significant improvement in 90-day survival [129]. In contrast, another retrospective cohort study in critically ill MERS patients indicated that macrolide therapy is not associated with a reduction in 90-day mortality rates or MERS-CoV RNA clearance [132]. Thus, current data are insufficient to draw any firm conclusions about the benefits of adjunctive azithromycin in COVID-19 patients. Furthermore, this antibiotic is known to prolong the QT interval and potentially increase the risk of sudden cardiac death [136], which is more of a concern for non-monitored outpatients receiving this therapy in combination with other QT-prolonging therapies.

\subsection{Hydroxychloroquine and Chloroquine}

It has been postulated that hydroxychloroquine and chloroquine exhibit immunomodulatory effects that theoretically may confer an anti-inflammatory response in patients with 
viral infections [137-140]. These drugs can reduce cytokine production, especially IL-1 and IL-6, and inhibit toll-like receptor signaling [141, 142]. A multicenter, parallel, openlabel, randomized trial indicated the potentially beneficial anti-inflammatory effect of hydroxychloroquine in patients with COVID-19 [143]. While adding hydroxychloroquine to the standard of care did not increase virus response, it did accelerate the alleviation of clinical symptoms, conceivably by reducing inflammation and recovery of lymphopenia. Symptomatic patients with elevated CRP and/or lymphopenia are the most likely COVID-19 patients to benefit from hydroxychloroquine. If these findings are confirmed in larger studies, hydroxychloroquine may be indicated to decrease the risk of progressive COVID-19 illness in patients, although this must await properly performed trials. However, as with azithromycin, this agent also prolongs the QT interval, and the combination of hydroxychloroquine and azithromycin could produce additive and potentially dangerous QT prolongation [144].

More recently, an observational study by Geleris et al. [145] analyzed data of 1376 patients who received hydroxychloroquine, 811 (58.9\%) received hydroxychloroquine and $565(41.1 \%)$ did not. The primary endpoint was the time from study baseline to intubation or death. The primary endpoint developed in 346 patients (25.1\%), and there was no significant association between hydroxychloroquine use and the composite primary endpoint (HR 1.04, 95\% CI 0.82-1.32). A multicentered, double-blind, placebo-controlled trial by Boulware et al. [146] evaluated the use of hydroxychloroquine as a potential agent for post-exposure prophylaxis in 821 asymptomatic adults with occupational or household exposure, $66 \%$ were healthcare workers. The primary outcome was to identify new COVID-19 infections between patients who received hydroxychloroquine or placebo. Within 4 days of exposure, patients were randomized to either a 5-day regimen of hydroxychloroquine or placebo. While there were slightly fewer infections in the hydroxychloroquine arm (11.8\% vs. $14.3 \%)$, the difference was not statistically significant (95\% CI -7.0 to $2.2 ; p=0.35$ ). This may imply that post-exposure prophylaxis is not effective in preventing symptomatic infection among patients who are exposed to known COVID-19-positive infections.

The FDA decided to retract emergency use authorization of these drugs on 15 June 2020. The basis of this decision is that hydroxychloroquine or chloroquine are unlikely to be effective in treating COVID-19, above and beyond the serious cardiac adverse events and several newly reported cases of methemoglobinemia associated with the use of these drugs in COVID-19 patients [147]. Additionally, earlier observations of decreased viral shedding with these drugs have not been consistently replicated. Preliminary results from the RECOVERY trial reported that hydroxychloroquine did not provide a significant difference in the primary endpoint of 28-day mortality $-25.7 \%$ in the hydroxychloroquine arm and $23.5 \%$ in the usual-care arm (HR 1.11, 95\% CI 0.98-1.26, $p=0.10$ ) [148]. In addition, there was no evidence of beneficial effects on hospital length of stay or the need for mechanical ventilation. Similarly, the ORCHID study, which evaluated the safety and effectiveness of hydroxychloroquine for the treatment of COVID-19 in hospitalized adults, was halted by the NIH due to the lack of evidence of efficacy [149]. Moreover, a double-blind, randomized phase IIb Brazilian study by Borba et al. evaluated the efficacy and safety of two different chloroquine dosages as adjunctive therapy in hospitalized patients with severe COVID-19 [150]. The 81 enrolled patients were randomized to receive either high-dose chloroquine (i.e. $600 \mathrm{mg}$ twice daily for 10 days) or low-dose chloroquine (i.e. $450 \mathrm{mg}$ twice daily on day 1 and once daily for 4 days). All patients received azithromycin, and some received oseltamivir. Interim analysis of the study revealed that the high-dose regimen was associated with more cardiac toxic effects (QTc $>500 \mathrm{~ms}$, $18.9 \%$ vs. $11.1 \%)$ and death (39\% vs. $15 \%)$, although the high-dose arm included more patients susceptible to cardiac complications. Thus, the high-dose regimen should not be recommended for the treatment of severe COVID19 , particularly in patients also receiving azithromycin and oseltamivir. The study continues to evaluate the low-dose regimen.

\subsection{Colchicine}

Colchicine is a potent oral anti-inflammatory medication that is indicated for the treatment of gout, familial Mediterranean fever, and pericarditis (off-label) [151]. Colchicine exhibits anti-inflammatory properties by inhibiting the polymerization of microtubes, and possibly through effects on cellular adhesion molecules and inflammatory chemokines [152]. Additionally, colchicine displays direct anti-inflammatory and immunomodulatory effects by inhibiting the NOD-, LRR- and pyrin domain-containing protein 3 (NLRP3) inflammasome and proinflammatory cytokines [153]. Given the important role of inflammation in severe COVID-19, colchicine may play a role in mitigating the cytokine storm and limiting multiorgan damage. However, a retrospective study of 14,520 patients based on a large healthcare computerized database found no significant difference in the rates of colchicine use between patients with a positive RT-PCR result for SARS-CoV- 2 and those with a negative result $(0.53 \%$ vs. $0.48 \%$ ) [153]. This suggests that colchicine may not have a protective role against a SARS-CoV-2 infection. It has also been hypothesized that colchicine may be harmful in COVID-19 patients [154]. At therapeutic doses, colchicine may decrease the release of surfactants by affecting alveolar 


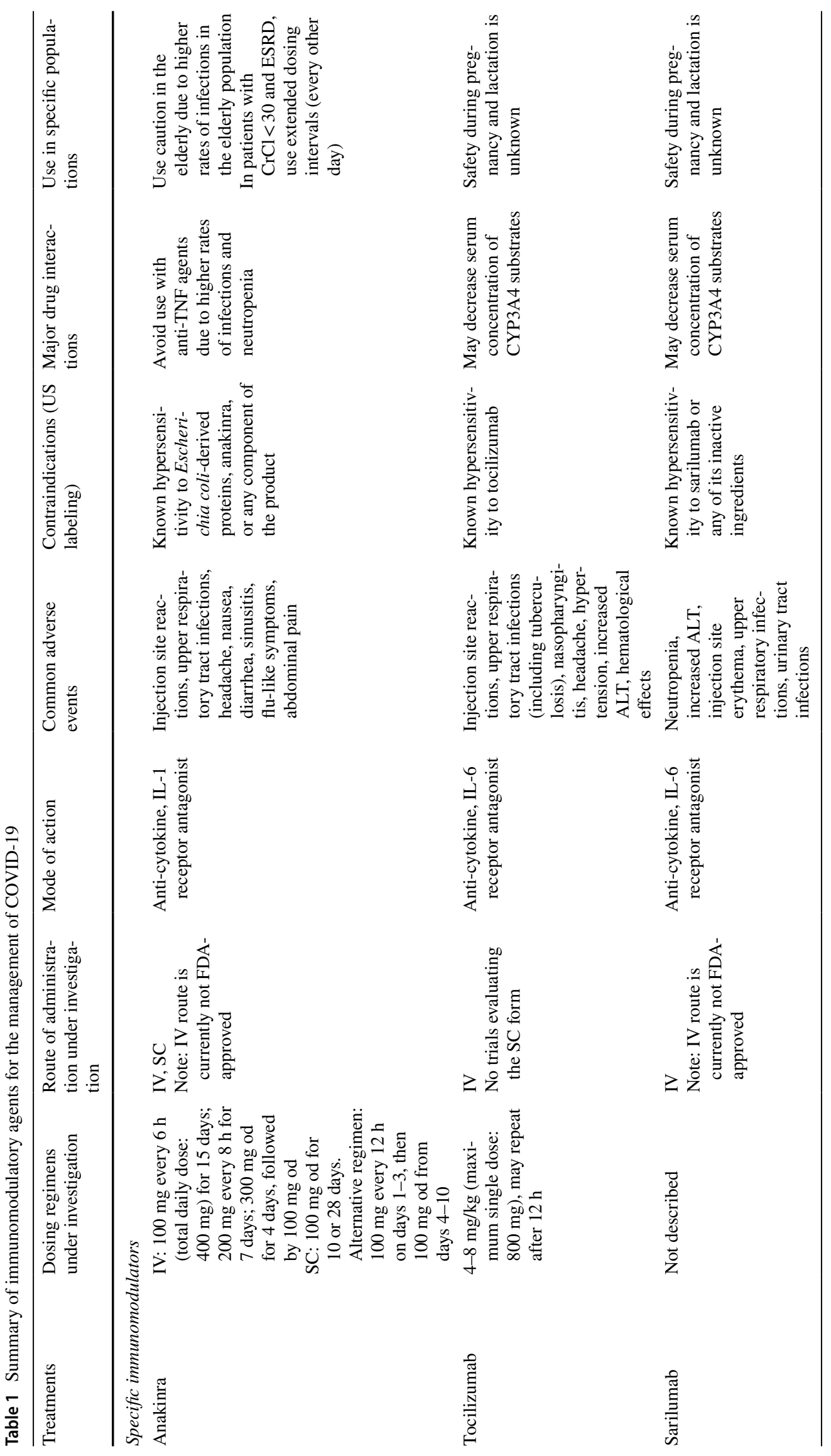




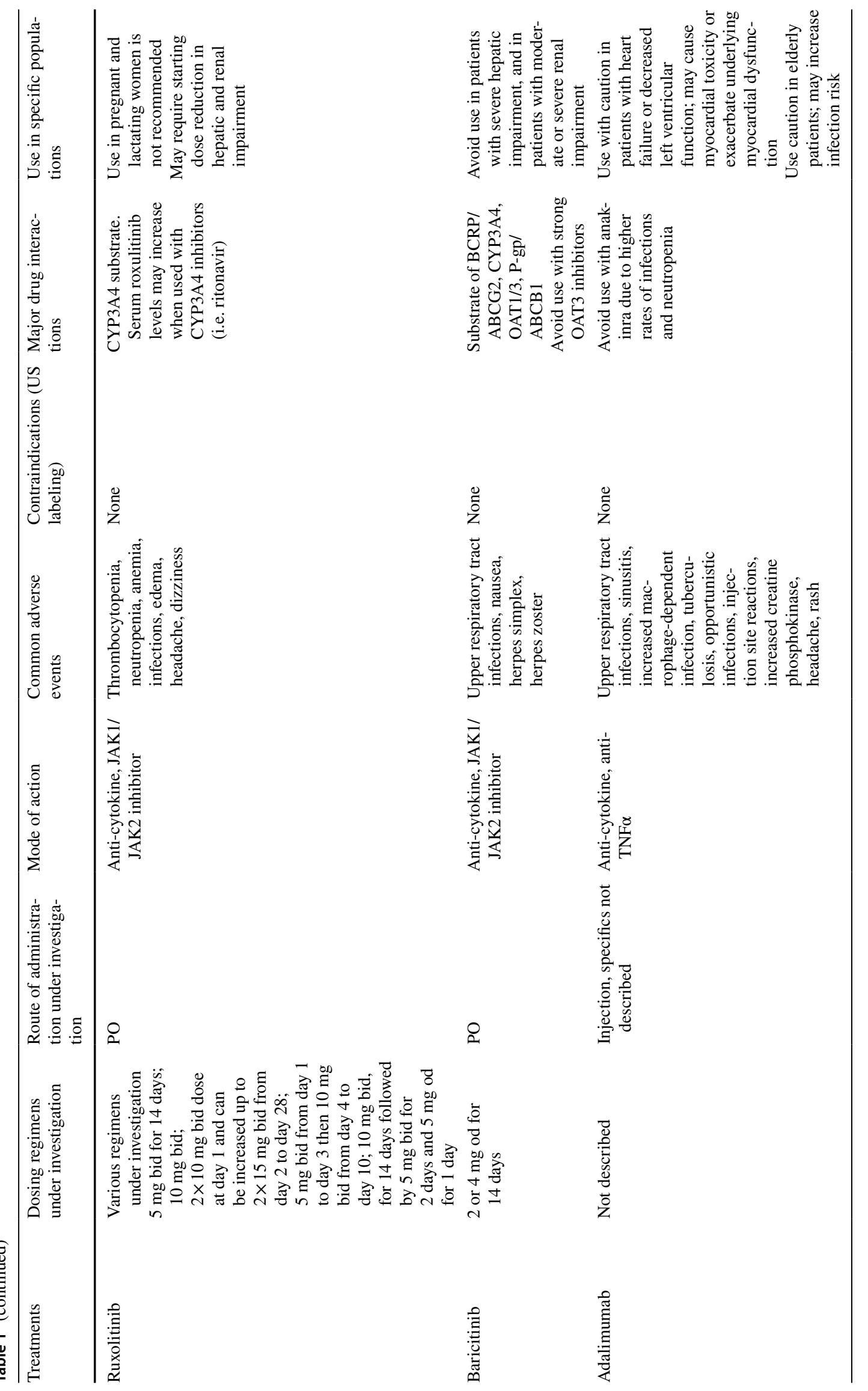




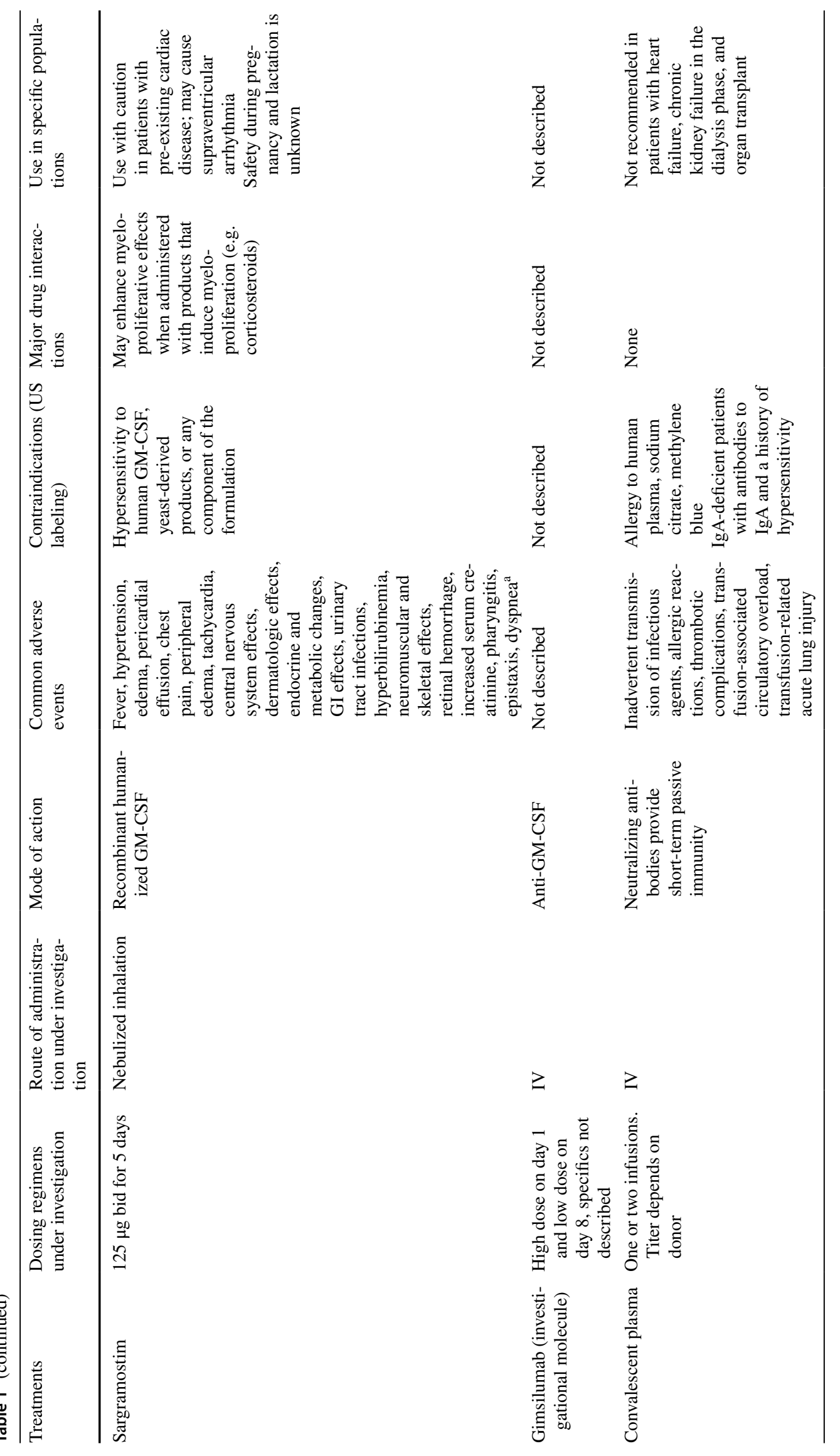




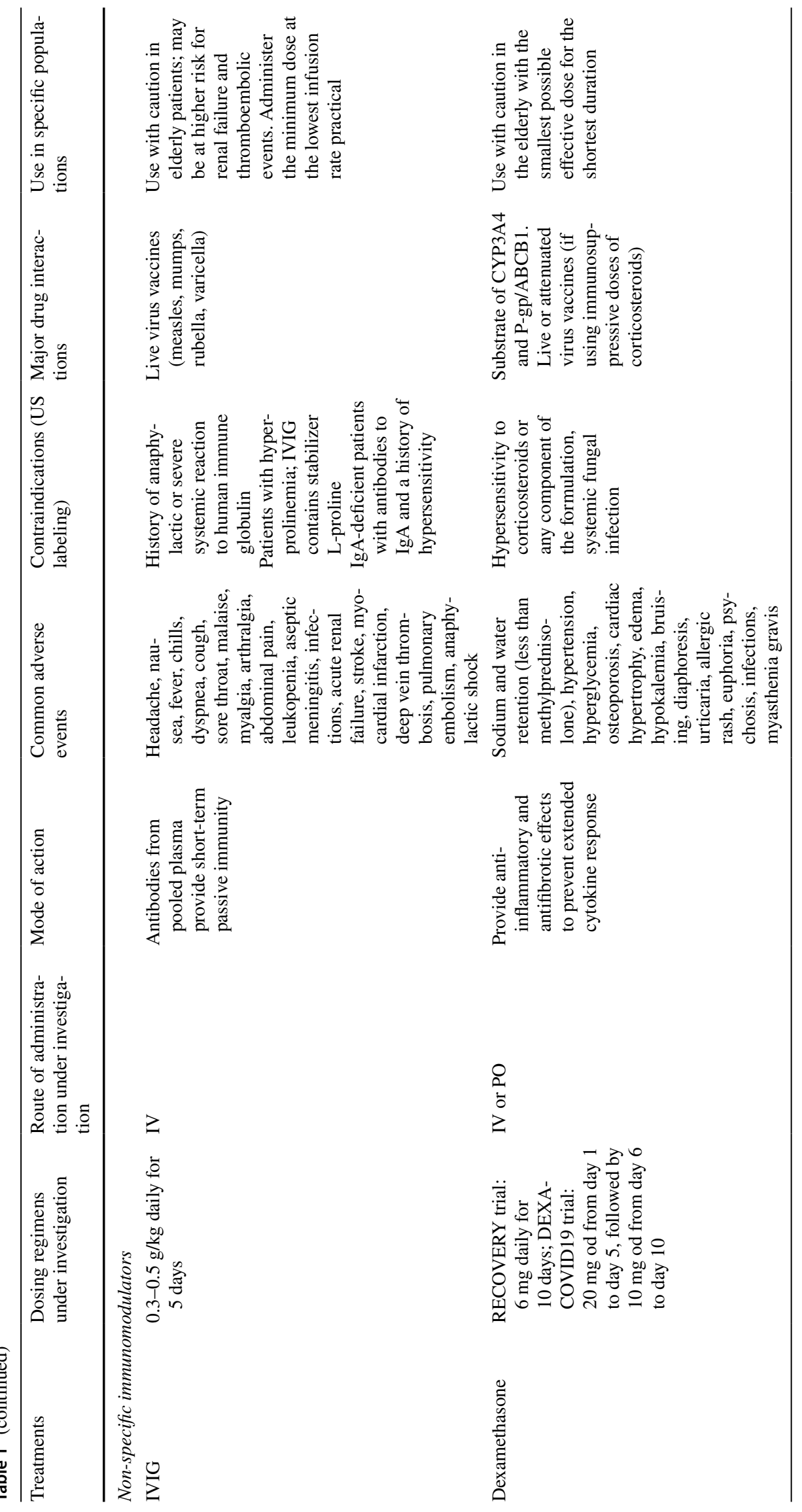




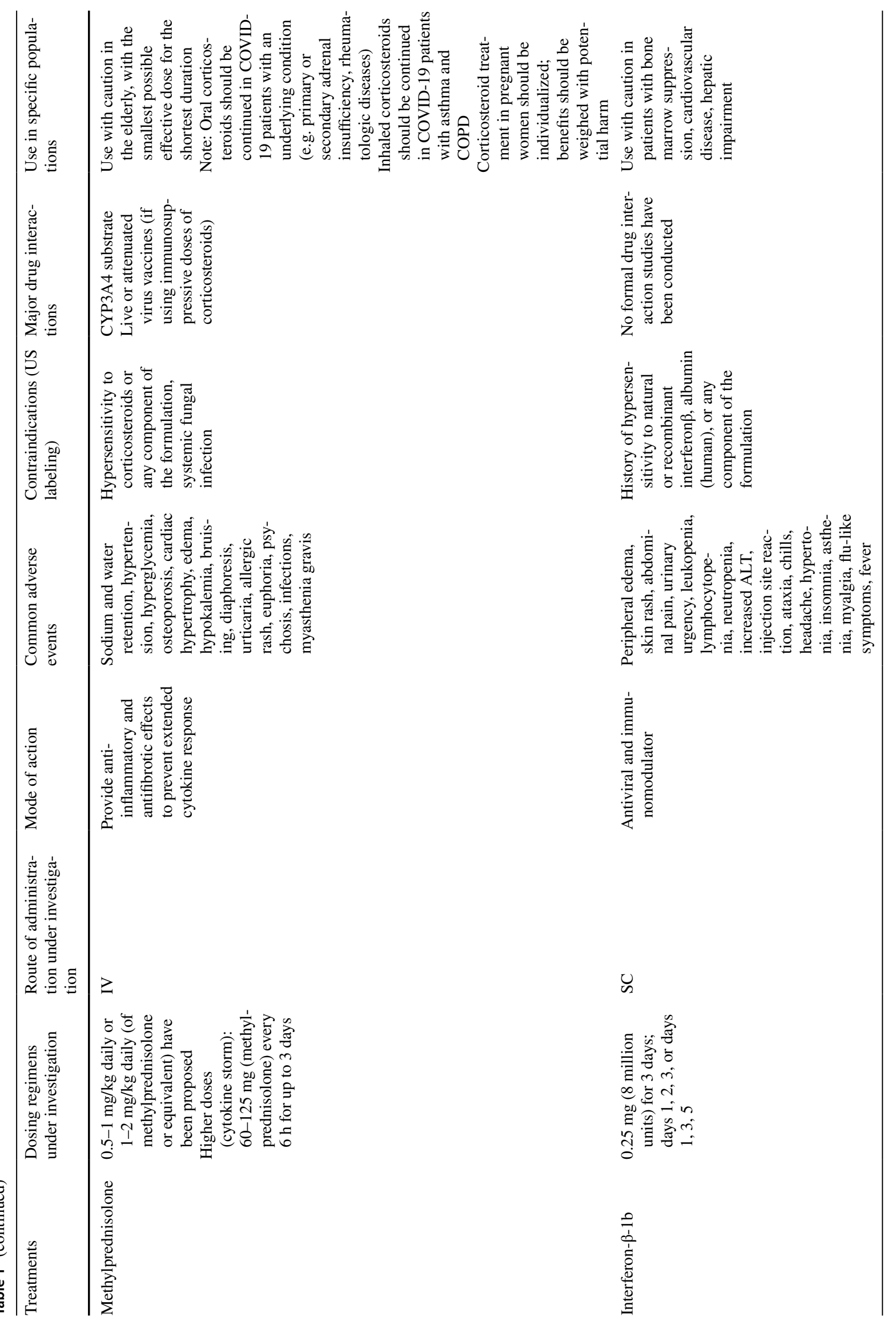




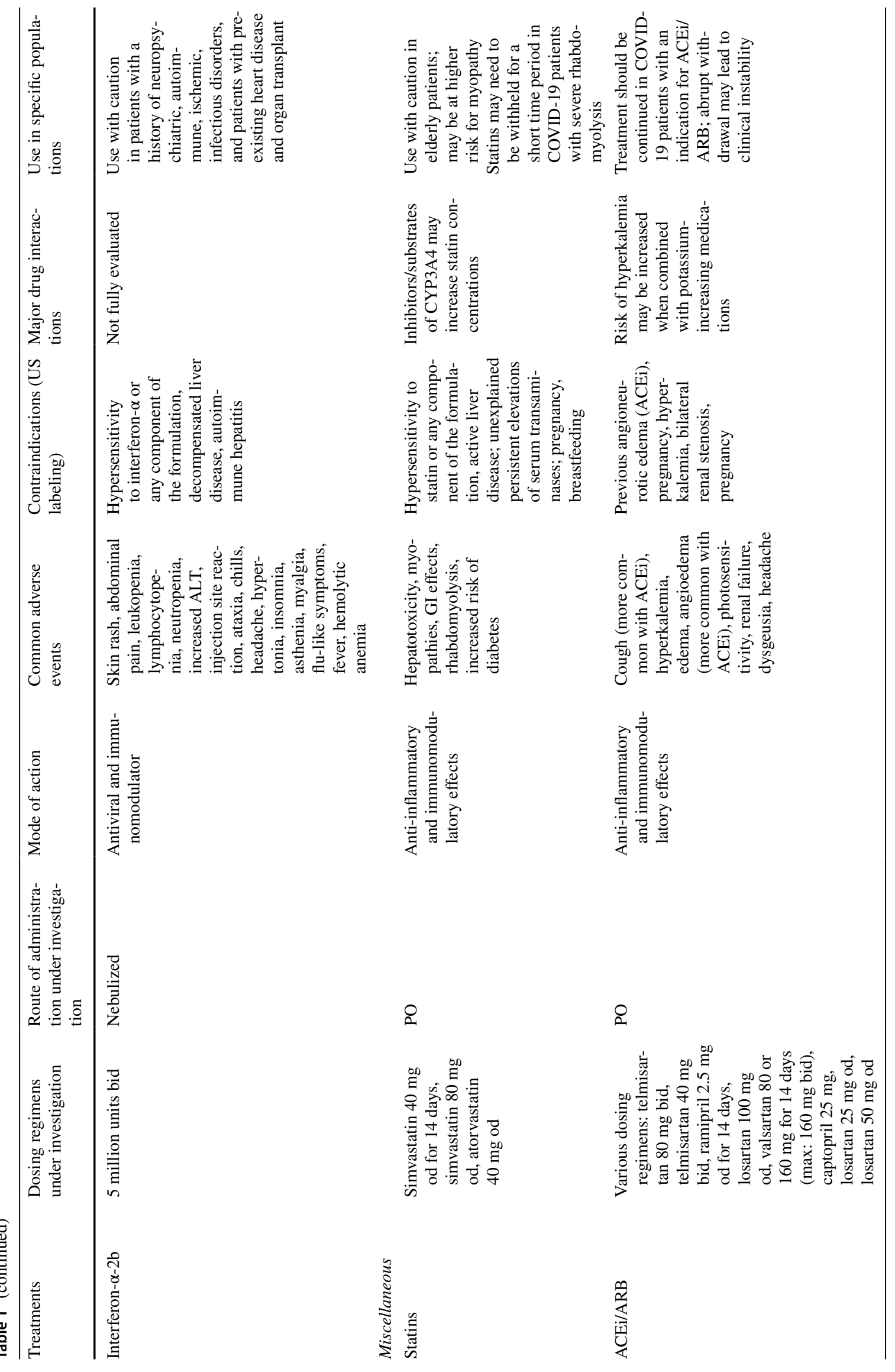




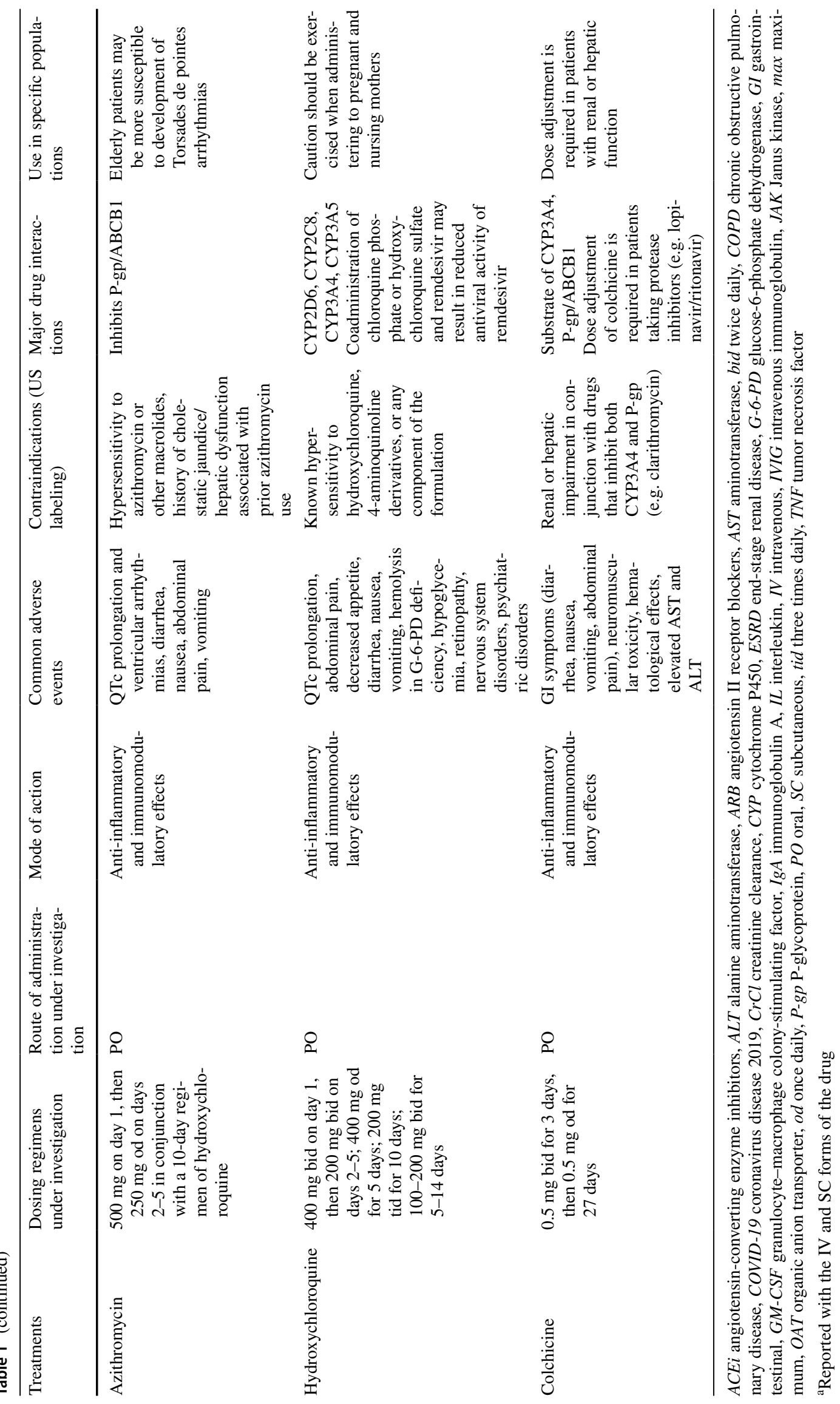


type II pneumocytes. At toxic doses, colchicine may further inhibit surfactant secretion, worsen ARDS, and cause multiorgan failure and disseminated intravascular coagulation.

COLCORONA is a randomized, double-blind, placebocontrolled trial that is currently evaluating the efficacy and safety of colchicine in adult COVID-19 patients who have at least one high-risk criterion (NCT04322682). The trial aims to enroll 6000 newly diagnosed patients and will assess the impact of colchicine treatment on rates of hospitalization or death from the syndrome 30 days after enrollment. Patients will receive colchicine $0.5 \mathrm{mg}$ twice daily for the first 3 days and then once daily for the remaining 27 days. Other trials are underway or planned (NCT04350320, NCT04326790, NCT04322565).

See Table 1 for a summary of the various pharmacoimmunomodulatory drugs.

\section{Conclusion}

COVID-19 is increasingly being recognized as a syndrome of viral replication and host inflammatory response. Effective pharmaco-immunomodulating strategies may help alleviate syndrome progression, especially in the more advanced stages of COVID-19. Considering the immune dysfunction and lymphopenia in COVID-19, several immunomodulators are under development or are being repurposed [155-157]. One plausible target is prostaglandin D2 (PGD2), which is normally upregulated in the airways of the elderly population, and is further augmented by SARS-CoV RNA, which stimulates the promoter of the cyclooxygenase (COX) genes. PGD2 is likely to play an important role in suppressing the host immune response to the virus by acting through the DP2 (CRTH2) receptor. In SARS-CoV-infected mice, PGD2 is reported to increase by two- to fivefold in the airways, and gradually increases with age [158]. PGD2 signaling through DP2 stimulates group 2 innate lymphoid cells (ILC2s) to secrete IL-13, which in return activates monocytic myeloid-derived suppressor cells (M-MDSC) to suppress the adaptive immune system [159]. MDSCs' mediated impairment of pathogen-specific adaptive immune responses have been demonstrated with Hemophilus influenzae respiratory infection [160]. Furthermore, ILC2s, despite their scarcity, are the dominant innate lymphoid cell population in the lung, indicating a key role as first responders and amplifiers upon immune challenge at this site [161]. Targeting PGD2/DP2 signaling holds potential as an immunotherapeutic approach for immune dysfunction and lymphopenia, characteristic features of COVID-19 disease. Ramatroban (Baynas ${ }^{\circledR}$ ) is a potent, reversible, and selective antagonist of PGD2/DP2 receptors that has been shown to inhibit PGD2-stimulated IL-13 secretion, with a half maximal inhibitory concentration $\left(\mathrm{IC}_{50}\right)$ of $118 \mathrm{nM}$ [162-164]. It has a well-established safety profile and has been used orally as a treatment for allergic rhinitis in Japan for the past 20 years. Hence, clinical trials investigating the role of ramatroban as a therapeutic agent in the context of COVID-19 are warranted.

With such novel targeted therapies in the pipeline, more options may become available for the treatment of COVID-19. Recent studies have demonstrated that hydroxychloroquine and chloroquine may not be effective in treating COVID-19, and the known and potential benefits of these drugs do not outweigh their known and potential risks. However, low-dose dexamethasone (6 mg once daily, orally or intravenously, for 10 days) has been shown to be effective in reducing deaths by one-third in patients on mechanical ventilation and by one-fifth in patients receiving oxygen only. Future research efforts should focus not only on the most relevant immunomodulatory strategies but also the optimal timing of such immunomodulatory interventions to maximize therapeutic effect.

\section{Declarations}

Conflict of interest John G. Rizk, Carl J. Lavie, Youssef Rizk, and Donald N. Forthal report they have no conflicts of interest to disclose relative to this research. Kamyar Kalantar-Zadeh has received honoraria and/or support from Abbott, Abbvie, ACI Clinical (Cara Therapeutics), Akebia, Alexion, Amgen, Ardelyx, American Society of Nephrology (ASN), Astra-Zeneca, Aveo, BBraun, Chugai, Cytokinetics, Daiichi, DaVita, Fresenius, Genentech, Haymarket Media, Hofstra Medical School, International Federation of Kidney Foundations (IFKF), International Society of Hemodialysis (ISH), International Society of Renal Nutrition and Metabolism (ISRNM), Japanese Society of Dialysis Therapy (JSDT), Hospira, Kabi, Keryx, Kissei, Novartis, OPKO, National Institutes of Health (NIH), National Kidney Foundation (NKF), Pfizer, Regulus, Relypsa, Resverlogix, Dr Schaer, Sandoz, Sanofi, Shire, Veterans' Affairs (VA), Vifor, UpToDate, and ZS-Pharma. Mandeep R. Mehra reports consulting relationships with Abbott, Medtronic, Janssen, Mesoblast, Portola, Bayer, NupulseCV, FineHeart, Leviticus, Roivant, Baim Institute for Clinical Research, and Intrexon (Triple Gene).

Funding The authors received no financial support for the research, authorship, and/or publication of this article.

\section{References}

1. Siddiqi HK, Mehra MR. COVID-19 illness in native and immunosuppressed states: a clinical-therapeutic staging proposal. J Heart Lung Transplant. 2020;39(5):405-7. https://doi. org/10.1016/j.healun.2020.03.012.

2. Rodríguez Y, Novelli L, Rojas M, et al. Autoinflammatory and autoimmune conditions at the crossroad of COVID-19. J Autoimmun. 2020. https://doi.org/10.1016/j.jaut.2020.102506.

3. Wu F, Zhao S, Yu B, et al. A new coronavirus associated with human respiratory disease in China [published correction appears 
in Nature. 2020;580(7803):E7]. Nature. 2020;579(7798):265-9. https://doi.org/10.1038/s41586-020-2008-3.

4. Huang C, Wang Y, Li X, Ren L, Zhao J, Hu Y, et al. Clinical features of patients infected with 2019 novel coronavirus in Wuhan. China Lancet. 2020;395:497-506.

5. Chan JF, Yuan S, Kok KH, To KK, Chu H, Yang J, et al. A familial cluster of pneumonia associated with the 2019 novel coronavirus indicating person-to-person transmission: a study of a family cluster. Lancet. 2020;395:514-23.

6. Wu C, Chen X, Cai Y, et al. Risk factors associated with acute respiratory distress syndrome and death in patients with coronavirus disease 2019 pneumonia in Wuhan. China JAMA Intern Med. 2020;180(7):1-11. https://doi.org/10.1001/jamaintern med.2020.0994.

7. Mahallawi WH, Khabour OF, Zhang Q, Makhdoum HM, Suliman BA. MERS-CoV infection in humans is associated with a pro-inflammatory Th1 and Th17 cytokine profile. Cytokine. 2018;104(8-13):24.

8. Wong CK, Lam CW, Wu AK, Ip WK, Lee NL, Chan IH, et al. Plasma inflammatory cytokines and chemokines in severe acute respiratory syndrome. Clin Exp Immunol. 2004;136:95-103.

9. Shi Y, Wang Y, Shao C, Huang J, Gan J, Huang X, et al. COVID-19 infection: the perspectives on immune responses. Cell Death Differ. 2020;27(5):1451-4. https://doi.org/10.1038/ s41418-020-0530-3.

10. Prompetchara E, Ketloy C, Palaga T. Immune responses in COVID-19 and potential vaccines: lessons learned from SARS and MERS epidemic. Asian Pac J Allergy Immunol. 2020;38(1):1-9. https://doi.org/10.12932/AP-200220-0772.

11. Mehta P, McAuley DF, Brown M, et al. COVID-19: consider cytokine storm syndromes and immunosuppression. Lancet. 2020;395(10229):1033-4. https://doi.org/10.1016/S0140 -6736(20)30628-0.

12. McGonagle D, O'Donnell JS, Sharif K, Emery P, Bridgewood C. Immune mechanisms of pulmonary intravascular coagulopathy in COVID-19 pneumonia. Lancet Rheumatol. 2020;2:e437-e445445.

13. Webster NR, Galley HF. Immunomodulation in the critically ill. Br J Anaesth. 2009;103(1):70-81. https://doi.org/10.1093/ bja/aep128.

14. National Research Council (US) Committee on New Directions in the Study of Antimicrobial Therapeutics: New Classes of Antimicrobials; National Research Council (US) Committee on New Directions in the Study of Antimicrobial Therapeutics: Immunomodulation. Treating Infectious Diseases in a Microbial World: Report of Two Workshops on Novel Antimicrobial Therapeutics. Washington, DC: National Academies Press (US); 2006

15. Merad M, Martin JC. Pathological inflammation in patients with COVID-19: a key role for monocytes and macrophages [published correction appears in Nat Rev Immunol. 2020;20(7):448]. Nat Rev Immunol. 2020;20(6):355-62. https://doi.org/10.1038/ s41577-020-0331-4.

16. Swedish Orphan Biovitrum AB. Kineret ${ }^{\circledR}$ (anakinra) injection, solution prescribing information. Stockholm: Swedish Orphan Biovitrum AB; 2018.

17. Monteagudo LA, Boothby A, Gertner E. Continuous intravenous anakinra infusion to calm the cytokine storm in macrophage activation syndrome. ACR Open Rheumatol. 2020;2(5):276-82. https://doi.org/10.1002/acr2.11135.

18. Schulert GS, Grom AA. Pathogenesis of macrophage activation syndrome and potential for cytokine-directed therapies. Annu Rev Med. 2015;66:145-59.

19. Shakoory B, Carcillo JA, Chatham WW, et al. Interleukin-1 receptor blockade is associated with reduced mortality in sepsis patients with features of macrophage activation syndrome: reanalysis of a prior phase III trial. Crit Care Med. 2016;44(2):275-81. https://doi.org/10.1097/CCM.0000000000 001402.

20. Aouba A, Baldolli A, Geffray L, et al. Targeting the inflammatory cascade with anakinra in moderate to severe COVID-19 pneumonia: case series. Ann Rheum Dis. 2020. https://doi.org/10.1136/ annrheumdis-2020-217706.

21. Huet T, Beaussier H, Voisin O, et al. Anakinra for severe forms of COVID-19: a cohort study. Lancet Rheumatol. 2020. https:// doi.org/10.1016/S2665-9913(20)30164-8.

22. Dimopoulos G, de Mast Q, Markou N, et al. Favorable anakinra responses in severe Covid-19 patients with secondary hemophagocytic lymphohistiocytosis. Cell Host Microbe. 2020;28(1):117-123.e1. https://doi.org/10.1016/j. chom.2020.05.007.

23. Cao X. COVID-19: immunopathology and its implications for therapy. Nat Rev Immunol. 2020;20(5):269-70. https://doi. org/10.1038/s41577-020-0308-3.

24. Kaly L, Rosner I. Tocilizumab — a novel therapy for non-organspecific autoimmune diseases. Best Pract Res Clin Rheumatol. 2012;26(1):157-65. https://doi.org/10.1016/j.berh.2012.01.001.

25. Xu X, Han M, Li T, et al. Effective treatment of severe COVID19 patients with tocilizumab. Proc Natl Acad Sci U S A. 2020;117(20):10970-5. https://doi.org/10.1073/pnas.20056 15117.

26. National Health Commission and State Administration of traditional Chinese medicine. Diagnosis and treatment protocol for novel coronavirus pneumonia. From China consulate website. https://busan.china-consulate.org/chn/zt/4/P02020031054844 7287942.pdf. Accessed 20 Mar 2020.

27. Luo P, Liu Y, Qiu L, Liu X, Liu D, Li J. Tocilizumab treatment in COVID-19: a single center experience. J Med Virol. 2020. https ://doi.org/10.1002/jmv.25801.

28. Alberici F, Delbarba E, Manenti C, et al. A single center observational study of the clinical characteristics and short-term outcome of 20 kidney transplant patients admitted for SARSCoV2 pneumonia. Kidney Int. 2020. https://doi.org/10.1016/j. kint.2020.04.002.

29. A multicenter, randomized controlled trial for the efficacy and safety of tocilizumab in the treatment of new coronavirus pneumonia (COVID-19). https://www.chictr.org.cn/showprojen .aspx?proj=49409. Accessed 15 June 2020.

30. Kevzara [package insert]. Bridgewater, NJ: Sanofi-aventis U.S. LLC; 2017. https://www.accessdata.fda.gov/drugsatfda_docs/ label/2017/761037s000lbl.pdf. Accessed 14 Apr 2020.

31. Sanofi, Regeneron Narrow Phase III Kevzara Trial to Critical COVID-19 Patients (2020). https://www.genengnews.com/news/ sanofi-regeneron-narrow-phase-iii-kevzara-trial-to-critical-covid -19-patients/. Accessed 11 May 2020.

32. Seif F, Khoshmirsafa M, Aazami H, et al. The role of JAK-STAT signaling pathway and its regulators in the fate of $\mathrm{T}$ helper cells. Cell Commun Signal. 2017;15:23.

33. Jakafi [package insert]. Wilmington, DE: Incyte Corporation; 2019. https://www.accessdata.fda.gov/drugsatfda_docs/label /2019/202192s017lbl.pdf. Accessed 14 Apr 2020.

34. Elli EM, Baratè C, Mendicino F, Palandri F, Palumbo GA. Mechanisms underlying the anti-inflammatory and immunosuppressive activity of ruxolitinib. Front Oncol. 2019;9:1186. https ://doi.org/10.3389/fonc.2019.01186.

35. Gaspari V, Zengarini C, Greco S, Vangeli V, Mastroianni A. Side effects of ruxolitinib in patients with SARS-CoV-2 infection: two case reports. Int J Antimicrob Agents. 2020. https://doi. org/10.1016/j.ijantimicag.2020.106023.

36. Richardson P, Griffin I, Tucker C, et al. Baricitinib as potential treatment for 2019-nCoV acute respiratory disease. Lancet. 
2020;395(10223):e30-e3131. https://doi.org/10.1016/S0140 $-6736(20) 30304-4$.

37. Olumiant [package insert]. Indianapolis, IN: Lilly USA, LLC; 2018. Available at: https://www.accessdata.fda.gov/drugsatfda _docs/label/2018/207924s000lbl.pdf. Accessed 19 Apr 2020.

38. Stebbing J, Phelan A, Griffin I, et al. COVID-19: combining antiviral and anti-inflammatory treatments. Lancet Infect Dis. 2020;20(4):400-2. https://doi.org/10.1016/S1473 -3099(20)30132-8.

39. Cj Jorgensen S, Ly Tse C, Burry L, Dresser LD. Baricitinib: a review of pharmacology, safety and emerging clinical experience in COVID-19. Pharmacotherapy. 2020. https://doi.org/10.1002/ phar.2438.

40. Cantini F, Niccoli L, Matarrese D, Nicastri E, Stobbione P, Goletti D. Baricitinib therapy in COVID-19: a pilot study on safety and clinical impact. J Infect. 2020. https://doi. org/10.1016/j.jinf.2020.04.017.

41. Lilly Begins Clinical Testing of Therapies for COVID-19. Press release. Lilly. https://investor.lilly.com/news-releases/newsrelease-details/lilly-begins-clinicaltesting-therapies-covid-19. Accessed 10 Apr 2020.

42. National Institutes of Health. Coronavirus disease 2019 (COVID19) treatment guidelines. https://www.covid19treatmentguideline s.nih.gov/). Accessed 11 May 2020.

43. NIH clinical trial testing antiviral remdesivir plus anti-inflammatory drug baricitinib for COVID-19 begins (2020). https:// www.nih.gov/news-events/news-releases/nih-clinical-trial-testi ng-antiviral-remdesivir-plus-anti-inflammatory-drug-baricitini b-covid-19-begins. Accessed 11 May 2020.

44. Lefebvre AL, McAuliffe L. Targeted immunomodulatory therapy: an overview. R I Med J (2013). 2016;99(12):19-22.

45. Wang L, He W, Yu X, et al. Coronavirus disease 2019 in elderly patients: characteristics and prognostic factors based on 4-week follow-up. J Infect. 2020. https://doi.org/10.1016/j. jinf.2020.03.019.

46. Hussell T, Pennycook A, Openshaw PJ. Inhibition of tumor necrosis factor reduces the severity of virus-specific lung immunopathology. Eur J Immunol. 2001;31:2566-73.

47. Haga S, Yamamoto N, Nakai-Murakami C, et al. Modulation of TNF-alpha-converting enzyme by the spike protein of SARS$\mathrm{CoV}$ and ACE2 induces TNF-alpha production and facilitates viral entry. Proc Natl Acad Sci USA. 2008;105(22):7809-14. https://doi.org/10.1073/pnas.0711241105.

48. Gerriets V, Bansal P, Khaddour K. Tumor necrosis factor (TNF) inhibitors. Treasure Island: StatPearls Publishing; 2020.

49. Feldmann M, Maini RN, Woody JN, et al. Trials of anti-tumour necrosis factor therapy for COVID-19 are urgently needed. Lancet. 2020. https://doi.org/10.1016/S0140-6736(20)30858-8.

50. Mahase E. Covid-19: what treatments are being investigated? BMJ. 2020;368:m1252. https://doi.org/10.1136/bmj.m1252.

51. Rösler B, Herold S. Lung epithelial GM-CSF improves host defense function and epithelial repair in influenza virus pneumonia-a new therapeutic strategy? Mol Cell Pediatr. 2016;3(1):29. https://doi.org/10.1186/s40348-016-0055-5.

52. Herold S, Hoegner K, Vadász I, et al. Inhaled granulocyte/macrophage colony-stimulating factor as treatment of pneumoniaassociated acute respiratory distress syndrome. Am J Respir Crit Care Med. 2014;189(5):609-11. https://doi.org/10.1164/ rccm.201311-2041LE.

53. Matute-Bello G, Liles WC, Radella F 2nd, Steinberg KP, Ruzinski JT, Hudson LD, Martin TR. Modulation of neutrophil apoptosis by granulocyte colony-stimulating factor and granulocyte/ macrophage colony-stimulating factor during the course of acute respiratory distress syndrome. Crit Care Med. 2000;28(1):1-7.

54. Overgaard CE, Schlingmann B, Dorsainvil White SC, Ward C, Fan X, Swarnakar S, Brown LA, Guidot DM, Koval M. The relative balance of GM-CSF and TGF- $\beta 1$ regulates lung epithelial barrier function. Am J Physiol Lung Cell Mol Physiol. 2015;308(12):L1212-L12231223.

55. Bhattacharya P, Budnick I, Singh M, et al. Dual role of GM-CSF as a pro-inflammatory and a regulatory cytokine: implications for immune therapy. J Interferon Cytokine Res. 2015;35(8):585-99. https://doi.org/10.1089/jir.2014.0149.

56. Zhou Y, Fu B, Zheng X, et al. Aberrant pathogenic GM-CSF+ $\mathrm{T}$ cells and inflammatory CD14+CD16+ monocytes in severe pulmonary syndrome patients of a new coronavirus [pre-print]. BioRxiv. 2020. https://doi.org/10.1101/2020.02.12.945576.

57. Paine R, Standiford TJ, Dechert RE, et al. A randomized trial of recombinant human granulocyte-macrophage colony stimulating factor for patients with acute lung injury. Crit Care Med. 2012;40(1):90-7. https://doi.org/10.1097/CCM.0b013e3182 2d7bf0.

58. Presneill JJ, Harris T, Stewart AG, Cade JF, Wilson JW. A randomized phase II trial of granulocyte-macrophage colony-stimulating factor therapy in severe sepsis with respiratory dysfunction. Am J Respir Crit Care Med. 2002;166:138-43.

59. Zhou Y, Fu B, Zheng X, et al. Pathogenic T cells and inflammatory monocytes incite inflammatory storm in severe COVID-19 patients. Natl Sci Rev. 2020. https://doi.org/10.1093/nsr/nwaa0 41.

60. Zhang W, Zhao Y, Zhang F, et al. The use of anti-inflammatory drugs in the treatment of people with severe coronavirus disease 2019 (COVID-19): the perspectives of clinical immunologists from China. Clin Immunol. 2020;214:108393. https://doi. org/10.1016/j.clim.2020.108393.

61. I-Mab seeks approval for Covid-19 trial in South Korea. https ://www.clinicaltrialsarena.com/news/i-mab-covid-19-drug-trial I. Accessed 14 May 2020.

62. Izana intiates study assessing namilumab for COVID-19. https ://www.pharmatimes.com/news/izana_intiates_study_assessing namilumab_for_covid-19_1337405. Accessed 14 May 2020.

63. Bloch EM, Bailey JA, Tobian AAR. Deployment of convalescent plasma for the prevention and treatment of COVID-19. J Clin Investig. 2020;130(6):2757-65. https://doi.org/10.1172/JCI13 8745.

64. Tiberghien $\mathrm{P}$, de Lambalarie X, Morel P, et al. Collecting and evaluating convalescent plasma for COVID-19 treatment: why and how. Vox Sang. 2020. https://doi.org/10.1111/vox.12926.

65. Roback JD, Guarner J. Convalescent plasma to treat COVID-19: possibilities and challenges [editorial]. JAMA. 2020. https://doi. org/10.1001/jama.2020.4940.

66. Casadevall A, Pirofski L. The convalescent sera option for containing COVID-19. J Clin Investig. 2020;130:1545-8. https://doi. org/10.1172/JCI138003.

67. Cunningham AC, Goh HP, Koh D. Treatment of COVID-19: old tricks for new challenges. Crit Care. 2020;24:91. https://doi. org/10.1186/s13054-020-2818-6.

68. Rojas M, Rodríguez Y, Monsalve DM, et al. Convalescent plasma in Covid-19: possible mechanisms of action. Autoimmun Rev. 2020;19(7):102554. https://doi.org/10.1016/j.autrev.2020.10255 4.

69. Soo YO, Cheng Y, Wong R, et al. Retrospective comparison of convalescent plasma with continuing high-dose methylprednisolone treatment in SARS patients. Clin Microbiol Infect. 2004;10(7):676-8. https://doi.org/10.111 1/j.1469-0691.2004.00956.x.

70. Arabi Y, Balkhy H, Hajeer AH, et al. Feasibility, safety, clinical, and laboratory effects of convalescent plasma therapy for patients with Middle East respiratory syndrome coronavirus infection: a study protocol. Springerplus. 2015;4:709. https:// doi.org/10.1186/s40064-015-1490-9. 
71. Hung IF, To KK, Lee CK, et al. Convalescent plasma treatment reduced mortality in patients with severe pandemic influenza A (H1N1) 2009 virus infection. Clin Infect Dis. 2011;52(4):44756. https://doi.org/10.1093/cid/ciq106.

72. Mair-Jenkins J, Saavedra-Campos M, Baillie JK, et al. The effectiveness of convalescent plasma and hyperimmune immunoglobulin for the treatment of severe acute respiratory infections of viral etiology: a systematic review and exploratory meta-analysis. J Infect Dis. 2015;211(1):80-90. https://doi.org/10.1093/infdis/ jiu396.

73. Shen C, Wang Z, Zhao F, et al. Treatment of 5 critically ill patients with COVID-19 with convalescent plasma. JAMA. 2020. https://doi.org/10.1001/jama.2020.4783.

74. Duan K, Liu B, Li C, et al. Effectiveness of convalescent plasma therapy in severe COVID-19 patients. Proc Natl Acad Sci USA. 2020. https://doi.org/10.1073/pnas.2004168117.

75. Joyner MJ, Wright RS, Fairweather D, et al. Early safety indicators of COVID-19 convalescent plasma in 5000 patients. J Clin Investig. 2020. https://doi.org/10.1172/JCI140200.

76. Li L, Zhang W, Hu Y, et al. Effect of convalescent plasma therapy on time to clinical improvement in patients with severe and lifethreatening COVID-19: a randomized clinical trial. JAMA. 2020. https://doi.org/10.1001/jama.2020.10044.

77. Kankakee, IL: CSL Behring LLC; 2007.https://www.fda.gov/ media/83304/download. Accessed 7 May 2020.

78. Stockman LJ, Bellamy R, Garner P. SARS: systemic review of treatment effects. PLoS Med. 2006;3:e343. https://doi. org/10.1371/journal.pmed.0030343.

79. Umapathi T, Kor AC, Venketasubramanian N, et al. Large artery ischaemic stroke in severe acute respiratory syndrome (SARS). J Neurol. 2004;251:1227-311. https://doi. org/10.1007/s00415-004-0519-9.

80. Ng KHL, Wu AKL, Cheng VCC, et al. Pulmonary artery thrombosis in a patient with severe acute respiratory syndrome. Postgrad Med J. 2005;81:e3.

81. Nguyen AA, Habiballah SB, Platt CD, Geha RS, Chou JS, McDonald DR. Immunoglobulins in the treatment of COVID-19 infection: proceed with caution! Clin Immunol. 2020;216:108459. https://doi.org/10.1016/j.clim.2020.108459.

82. Galeotti C, Kaveri SV, Bayry J. IVIG-mediated effector functions in autoimmune and inflammatory diseases. Int Immunol. 2017;29(11):491-8. https://doi.org/10.1093/intimm/dxx039.

83. Cao W, Liu X, Bai T, et al. High-dose intravenous immunoglobulin as a therapeutic option for deteriorating patients with coronavirus disease 2019. Open Forum Infect Dis. 2020;7(3):ofaa102. https://doi.org/10.1093/ofid/ofaa102.

84. Xie $\mathrm{Y}, \mathrm{Cao} \mathrm{S}$, Dong $\mathrm{H}$, et al. Effect of regular intravenous immunoglobulin therapy on prognosis of severe pneumonia in patients with COVID-19. J Infect. 2020. https://doi. org/10.1016/j.jinf.2020.03.044.

85. Alhazzani W, Møller MH, Arabi YM, et al. Surviving sepsis campaign: guidelines on the management of critically ill adults with coronavirus disease 2019 (COVID-19). Crit Care Med. 2020;48(6):e440-e46969. https://doi.org/10.1097/CCM.00000 00000004363.

86. Russell CD, Millar JE, Baillie JK. Clinical evidence does not support corticosteroid treatment for 2019-nCoV lung injury. Lancet. 2020;395(10223):473-5. https://doi.org/10.1016/ S0140-6736(20)30317-2.

87. Monton C, Ewig S, Torres A, El-Ebiary M, Filella X, Rañó A, Xaubet A. Role of glucocorticoids on inflammatory response in nonimmunosupressed patients with pneumonia: a pilot study. Eur Respir J. 1999;14:218-20.

88. Franchimont D, Kino T, Galon J, Meduri GU, Chrousos G. Glucocorticoids and inflammation revisited: the state of the art. NIH clinical staff conference. Neuroimmunomodulation. 2002-2003;10:247-60.

89. Hylands M, Moller MH, Asfar P, et al. A systematic review of vasopressor blood pressure targets in critically ill adults with hypotension. Can J Anaesth. 2017;64:703-15. https://doi. org/10.1007/s12630-017-0877-1.

90. Farkas J. Internet Book of Critical Care. https://emcrit.org/ ibcc/COVID19/. Accessed 7 May 2020.

91. Shang L, Zhao J, Hu Y, et al. On the use of corticosteroids for 2019-nCoV pneumonia. Lancet. 2020;395:683-4. https:// doi.org/10.1016/S0140-6736(20)30361-5(Epub 2020 Feb 12 PMID: 32122468).

92. Villar J, Confalonieri M, Pastores S, Meduri G, Umberto MD. Rationale for prolonged corticosteroid treatment in the acute respiratory distress syndrome caused by coronavirus disease 2019. Crit Care Explor. 2020;2(4):e0111. https://doi. org/10.1097/CCE.0000000000000111.

93. Rodrigo C, Leonardi-Bee J, Nguyen-Van-Tam J, Lim WS. Corticosteroids as adjunctive therapy in the treatment of influenza. Cochrane Database Syst Rev. 2016. https://doi. org/10.1002/14651858.CD010406.pub2(PubMed PMID: 26950335).

94. Arabi YM, Mandourah Y, Al-Hameed F, Sindi AA, Almekhlafi GA, Hussein MA, et al. Corticosteroid therapy for critically ill patients with Middle East respiratory syndrome. Am J Respir Crit Care Med. 2018;197(6):757-67. https://doi.org/10.1164/ rccm.201706-11720C.

95. World Health Organization. Clinical management of severe acute respiratory infection (SARI) when COVID-19 disease is suspected. Interim guidance. 13 Mar 2020. https://www.who.int/ publications-detail/clinical-management-of-severe-acute-respi ratory-infection-when-novel-coronavirus-(ncov)-infection-issuspected. Accessed 19 Mar 2020.

96. Centers for Disease Control. Healthcare professionals: frequently asked questions and answers. https://www.cdc.gov/coronaviru s/2019-ncov/hcp/faq.html. Accessed 7 Apr 2020.

97. Low-cost dexamethasone reduces death by up to one third in hospitalised patients with severe respiratory complications of COVID-19. https://www.recoverytrial.net/files/recovery_dexam ethasone_statement_160620_v2final.pdf. Accessed 20 June 2020.

98. Villar J, Ferrando C, Martínez D, et al. Dexamethasone treatment for the acute respiratory distress syndrome: a multicentre, randomised controlled trial. Lancet Respir Med. 2020;8(3):267-76. https://doi.org/10.1016/S2213-2600(19)30417-5.

99. Wang Y, Jiang W, He Q, et al. Early, low-dose and short-term application of corticosteroid treatment in patients with severe COVID-19 pneumonia: single-center experience from Wuhan, China. medRxiv. 2020. https://doi.org/10.1101/2020.03.06.20032 342.

100. Sallard E, Lescure FX, Yazdanpanah Y, Mentre F, Peiffer-Smadja N. Type 1 interferons as a potential treatment against COVID-19. Antiviral Res. 2020;178:104791. https://doi.org/10.1016/j.antiv iral.2020.104791.

101. Lokugamage KG, Hage A, Schindewolf C, Rajsbaum R, Menachery VD. SARS-CoV-2 is sensitive to type I interferon pretreatment. Preprint. bioRxiv. 2020;2020.03.07.982264. Published 2020 Apr 9. https://doi.org/10.1101/2020.03.07.982264.

102. Totura AL, Bavari S. Broad-spectrum coronavirus antiviral drug discovery. Expert Opin Drug Discov. 2019;14(4):397-412. https ://doi.org/10.1080/17460441.2019.1581171.

103. Loutfy MR, Blatt LM, Siminovitch KA, et al. Interferon alfacon-1 plus corticosteroids in severe acute respiratory syndrome: a preliminary study. JAMA. 2003;290(24):3222-8. https ://doi.org/10.1001/jama.290.24.3222. 
104. Omrani AS, Saad MM, Baig K, et al. Ribavirin and interferon alfa-2a for severe Middle East respiratory syndrome coronavirus infection: a retrospective cohort study [published correction appears in Lancet Infect Dis. 2015;211(2):13]. Lancet Infect Dis. 2014;14(11):1090-5. https://doi.org/10.1016/S1473 -3099(14)70920-X.

105. Chen L, Shi M, Deng Q, et al. A multi-center randomized prospective study on the treatment of infant bronchiolitis with interferon $\alpha 1 b$ nebulization [published correction appears in PLoS One. 2020;15(4):e0231911]. PLoS ONE. 2020;15(2):e0228391. https://doi.org/10.1371/journal.pone.0228391.

106. Hung IF, Lung KC, Tso EY, et al. Triple combination of interferon beta- $1 \mathrm{~b}$, lopinavir-ritonavir, and ribavirin in the treatment of patients admitted to hospital with COVID-19: an open-label, randomised, phase 2 trial. Lancet. 2020;395(10238):1695-704. https://doi.org/10.1016/S0140-6736(20)31042-4.

107. Zhou Q, Chen V, Shannon CP, et al. Interferon- $\alpha 2 b$ treatment for COVID-19. Front Immunol. 2020;11:1061. https://doi. org/10.3389/fimmu.2020.01061.

108. Dashti-Khavidaki S, Khalili H. Considerations for statin therapy in patients with COVID-19. Pharmacotherapy. 2020. https://doi. org/10.1002/phar.2397.

109. Massachusetts General Hospital COVID-19 Treatment Guidance Version 1.0. https://medtube.net/infectious-diseases/medic al-documents/26086-covid19-treatment-guidelines-by-massa chusetts-general-hospital. Accessed 17 Mar 2020.

110. Schönbeck U, Libby P. Inflammation, immunity, and HMG-CoA reductase inhibitors: statins as antiinflammatory agents? Circulation. 2004;109(21 Suppl 1):II18-II26. https://doi.org/10.1161/01. CIR.0000129505.34151.23.

111. Troeman DP, Postma DF, van Werkhoven CH, Oosterheert JJ. The immunomodulatory effects of statins in community-acquired pneumonia: a systematic review. J Infect. 2013;67(2):93-101. https://doi.org/10.1016/j.jinf.2013.04.015.

112. Yuan S. Statins may decrease the fatality rate of Middle East respiratory syndrome infection. mBio. 2015;6(4):e01120-15.

113. DeDiego ML, Nieto-Torres JL, Regla-Nava JA, JimenezGuardeño JM, Fernandez-Delgado R, Fett C, et al. Inhibition of NF- $\kappa \mathrm{B}$-mediated inflammation in severe acute respiratory syndrome coronavirus-infected mice increases survival. J Virol. 2014;88(2):913.

114. Totura AL, Whitmore A, Agnihothram S, et al. Toll-like receptor 3 signaling via TRIF contributes to a protective innate immune response to severe acute respiratory syndrome coronavirus infection. mBio. 2015;6(3):e00638-15. https://doi.org/10.1128/ mBio.00638-15.

115. Sheahan T, Morrison TE, Funkhouser W, et al. MyD88 is required for protection from lethal infection with a mouseadapted SARS-CoV. PLoS Pathog. 2008;4(12):e1000240. https ://doi.org/10.1371/journal.ppat.1000240.

116. Yuan X, Deng Y, Guo X, Shang J, Zhu D, Liu H. Atorvastatin attenuates myocardial remodeling induced by chronic intermittent hypoxia in rats: partly involvement of TLR-4/MYD88 pathway. Biochem Biophys Res Commun. 2014;446(1):292-7. https ://doi.org/10.1016/j.bbrc.2014.02.091.

117. Lala A, Johnson KW, Januzzi JL, et al. Prevalence and impact of myocardial injury in patients hospitalized with COVID-19 infection. J Am Coll Cardiol. 2020. https://doi.org/10.1016/j. jacc.2020.06.007.

118. De Spiegeleer A, Bronselaer A, Teo JT, et al. The effects of ARBs, ACEIs and statins on clinical outcomes of COVID-19 infection among nursing home residents. J Am Med Dir Assoc. 2020. https://doi.org/10.1016/j.jamda.2020.06.018.
119. Chang Y, Wei W. Angiotensin II in inflammation, immunity and rheumatoid arthritis. Clin Exp Immunol. 2015;179(2):137-45. https://doi.org/10.1111/cei.12467.

120. Lu R, Zhao X, Li J, et al. Genomic characterisation and epidemiology of 2019 novel coronavirus: implications for virus origins and receptor binding. Lancet. 2020;395(10224):565-74. https:// doi.org/10.1016/S0140-6736(20)30251-8.

121. Kuba K, Imai Y, Rao S, et al. A crucial role of angiotensin converting enzyme 2 (ACE2) in SARS coronavirus-induced lung injury. Nat Med. 2005;11(8):875-9. https://doi.org/10.1038/ nm1267.

122. Imai $\mathrm{Y}$, Kuba K, Rao S, et al. Angiotensin-converting enzyme 2 protects from severe acute lung failure. Nature. 2005;436(7047):112-6. https://doi.org/10.1038/nature03712.

123. Tikellis C, Bernardi S, Burns WC. Angiotensin-converting enzyme 2 is a key modulator of the renin-angiotensin system in cardiovascular and renal disease. Curr Opin Nephrol Hypertens. 2011;20(1):62-8. https://doi.org/10.1097/MNH.0b013e3283 $41164 a$.

124. Reynolds HR, Adhikari S, Pulgarin C, et al. Renin-angiotensin-aldosterone system inhibitors and risk of covid-19. N Engl J Med. 2020;382(25):2441-8. https://doi.org/10.1056/NEJMo a2008975.

125. Mancia G, Rea F, Ludergnani M, Apolone G, Corrao G. Renin-angiotensin-aldosterone system blockers and the risk of covid-19. N Engl J Med. 2020;382(25):2431-40. https://doi. org/10.1056/NEJMoa2006923.

126. Curfman G. Renin-angiotensin-aldosterone inhibitors and susceptibility to and severity of COVID-19. JAMA. 2020. https:// doi.org/10.1001/jama.2020.11401.

127. Bermejo-Martin JF, Kelvin DJ, Eiros JM, et al. Macrolides for the treatment of severe respiratory illness caused by novel H1N1 swine influenza viral strains. J Infect Dev Ctries. 2009;3:159-61.

128. Zhang Y, Dai J, Jian H, et al. Effects of macrolides on airway microbiome and cytokine of children with bronchiolitis: a systematic review and meta-analysis of randomized controlled trials. Microbiol Immunol. 2019;63:343-9. https://doi. org/10.1111/1348-0421.12726).

129. Kawamura K, Ichikado K, Takaki M, et al. Adjunctive therapy with azithromycin for moderate and severe acute respiratory distress syndrome: a retrospective, propensity score-matching analysis of prospectively collected data at a single center. Int J Antimicrob Agents. 2018;51:918-24. https://doi.org/10.1016/j. ijantimicag.2018.02.009.

130. Kuo CH, Lee MS, Kuo HF, et al. Azithromycin suppresses Th1and Th2-related chemokines IP-10/MDC in human monocytic cell line. J Microbiol Immunol Infect. 2019;52:872-9. https:// doi.org/10.1016/j.jmii.2019.10.001.

131. Abrams EM, Raissy HH. Emerging therapies in the treatment of early childhood wheeze. Pediatr Allergy Immunol Pulmonol. 2019;32:78-80. https://doi.org/10.1089/ped.2019.1043.

132. Arabi YM, Deeb AM, Al-Hameed F, et al. Macrolides in critically ill patients with Middle East respiratory syndrome. Int J Infect Dis. 2019;81:184-90. https://doi.org/10.1016/j. ijid.2019.01.041.

133. Ishaqui AA, Khan AH, Sulaiman SAS, et al. Assessment of efficacy of oseltamivir-azithromycin combination therapy in prevention of Influenza-A (H1N1)pdm09 infection complications and rapidity of symptoms relief. Expert Rev Respir Med. 2020;14(5):533-41. https://doi.org/10.1080/17476 348.2020.1730180.

134. Schogler A, Kopf BS, Edwards MR, et al. Novel antiviral properties of azithromycin in cystic fibrosis airway epithelial cells. Eur Respir J. 2015;45:428-39. https://doi.org/10.1183/09031 936.00102014. 
135. Lee N, Wong CK, Chan MCW, et al. Anti-inflammatory effects of adjunctive macrolide treatment in adults hospitalized with influenza: a randomized controlled trial. Antivir Res. 2017;144:4856. https://doi.org/10.1016/j.antiviral.2017.05.008.

136. Ray WA, Murray KT, Hall K, Arbogast PG, Stein CM. Azithromycin and the risk of cardiovascular death. N Engl J Med. 2012;366(20):1881-900. https://doi.org/10.1056/NEJMoa1003 833.

137. Devaux CA, Rolain JM, Colson P, et al. New insights on the antiviral effects of chloroquine against coronavirus: what to expect for COVID-19? Int J Antimicrob Agents. 2020;55(5):105938. https://doi.org/10.1016/j.ijantimicag.2020.105938.

138. Yao X, Ye F, Zhang M, et al. In vitro antiviral activity and projection of optimized dosing design of hydroxychloroquine for the treatment of severe acute respiratory syndrome coronavirus 2 (SARS-CoV-2). Clin Infect Dis. 2020. https://doi.org/10.1093/ $\mathrm{cid} / \mathrm{ciaa} 237$.

139. Sahraei Z, Shabani M, Shokouhi S, et al. Aminoquinolines against coronavirus disease 2019 (COVID-19): chloroquine or hydroxychloroquine. Int J Antimicrob Agents. 2020;55(4):105945. https ://doi.org/10.1016/j.ijantimicag.2020.105945.

140. Zhou D, Dai SM, Tong Q. COVID-19: a recommendation to examine the effect of hydroxychloroquine in preventing infection and progression. J Antimicrob Chemother. 2020;75(7):1667-700. https://doi.org/10.1093/jac/dkaa114.

141. Ben-Zvi I, Kivity S, Langevitz P, Shoenfeld Y. Hydroxychloroquine: from malaria to autoimmunity. Clin Rev Allergy Immunol. 2012;42(2):145-53. https://doi.org/10.1007/s12016-010-8243-x.

142. Bonam SR, Muller S, Bayry J, Klionsky DJ. Autophagy as an emerging target for COVID-19: lessons from an old friend, chloroquine. Autophagy. 2020. https://doi.org/10.1080/15548 627.2020.1779467.

143. Tang W, Cao Z, Han M, et al. Hydroxychloroquine in patients with mainly mild to moderate coronavirus disease 2019: open label, randomised controlled trial. BMJ. 2020;369:m1849. https ://doi.org/10.1136/bmj.m1849.

144. Giudicessi JR, Noseworthy PA, Friedman PA, Ackerman MJ. Urgent guidance for navigating and circumventing the QTc-prolonging and torsadogenic potential of possible pharmacotherapies for coronavirus disease 19 (COVID-19). Mayo Clin Proc. 2020. https://doi.org/10.1016/j.mayocp.2020.03.024.

145. Geleris J, Sun Y, Platt J, et al. Observational study of hydroxychloroquine in hospitalized patients with covid-19. N Engl J Med. 2020;382(25):2411-8. https://doi.org/10.1056/NEJMo a2012410.

146. Boulware DR, Pullen MF, Bangdiwala AS, et al. A randomized trial of hydroxychloroquine as postexposure prophylaxis for covid-19. N Engl J Med. 2020. https://doi.org/10.1056/NEJMo a2016638.

147. Letter revoking EUA for chloroquine phosphate and hydroxychloroquine sulfate. 2020. https://www.fda.gov/media/138945/ download. Accessed 20 Jun 2020

148. Low-cost dexamethasone reduces death by up to one third in hospitalised patients with severe respiratory complications of COVID-19. 2020. https://www.recoverytrial.net/news/low-costdexamethasone-reduces-death-by-up-to-one-third-in-hospitalis ed-patients-with-severe-respiratory-complications-of-covid-19. Accessed 20 Jun 2020.

149. NIH halts clinical trial of hydroxychloroquine. 2020. https:// www.nih.gov/news-events/news-releases/nih-halts-clinical-trial -hydroxychloroquine. Accessed 20 Jun 2020.

150. Borba MGS, Val FFA, Sampaio VS, et al. Effect of high vs low doses of chloroquine diphosphate as adjunctive therapy for patients hospitalized with severe acute respiratory syndrome coronavirus 2 (SARS-CoV-2) infection: a randomized clinical trial. JAMA Netw Open. 2020;3(4):e208857. https://doi.org/10.1001/ jamanetworkopen.2020.8857.

151. Colcrys [package insert]. Philadelphia, PA: AR Scientific, Inc.; 2009. https://www.accessdata.fda.gov/drugsatfda_docs/label /2009/022353lbl.pdf. Accessed 20 Apr 2020.

152. Gasparyan AY, Ayvazyan L, Yessirkepov M, Kitas GD. Colchicine as an anti-inflammatory and cardioprotective agent. Expert Opin Drug Metab Toxicol. 2015;11(11):1781-94. https://doi. org/10.1517/17425255.2015.1076391.

153. Gendelman O, Amital H, Bragazzi NL, Watad A, Chodick G. Continuous hydroxychloroquine or colchicine therapy does not prevent infection with SARS-CoV-2: insights from a large healthcare database analysis. Autoimmun Rev. 2020;19(7):102566. https://doi.org/10.1016/j.autrev.2020.102566.

154. Cumhur Cure M, Kucuk A, Cure E. Colchicine may not be effective in COVID-19 infection; it may even be harmful? Clin Rheumatol. 2020;39(7):2101-2. https://doi.org/10.1007/s1006 7-020-05144-x.

155. Bonam SR, Kaveri SV, Sakuntabhai A, Gilardin L, Bayry J. Adjunct immunotherapies for the management of severely Ill COVID-19 patients. Cell Rep Med. 2020;1(2):100016. https:// doi.org/10.1016/j.xcrm.2020.100016.

156. Alijotas-Reig J, Esteve-Valverde E, Belizna C, et al. Immunomodulatory therapy for the management of severe COVID- 19 . Beyond the anti-viral therapy: a comprehensive review. Autoimmun Rev. 2020;19(7):102569. https://doi.org/10.1016/j.autre v.2020.102569.

157. Sun X, Wang T, Cai D, et al. Cytokine storm intervention in the early stages of COVID-19 pneumonia. Cytokine Growth Factor Rev. 2020;53:38-42. https://doi.org/10.1016/j.cytog fr.2020.04.002

158. Zhao J, Zhao J, Legge K, Perlman S. Age-related increases in $\mathrm{PGD}(2)$ expression impair respiratory DC migration, resulting in diminished $\mathrm{T}$ cell responses upon respiratory virus infection in mice. J Clin Investig. 2011;121(12):4921-30. https://doi. org/10.1172/JCI59777.

159. Trabanelli S, Chevalier MF, Martinez-Usatorre A, et al. Tumourderived PGD2 and NKp30-B7H6 engagement drives an immunosuppressive ILC2-MDSC axis. Nat Commun. 2017;8(1):593. https://doi.org/10.1038/s41467-017-00678-2.

160. De Santo C, Salio M, Masri SH, et al. Invariant NKT cells reduce the immunosuppressive activity of influenza A virus-induced myeloid-derived suppressor cells in mice and humans. J Clin Investig. 2008;118(12):4036-48. https://doi.org/10.1172/JCI36 264.

161. Mindt BC, Fritz JH, Duerr CU. Group 2 innate lymphoid cells in pulmonary immunity and tissue homeostasis. Front Immunol. 2018;9:840. https://doi.org/10.3389/fimmu.2018.00840.

162. Kupczyk M, Kuna P. Targeting the $\mathrm{PGD}_{2} / \mathrm{CRTH} 2 / \mathrm{DP} 1$ signaling pathway in asthma and allergic disease: current status and future perspectives. Drugs. 2017;77(12):1281-94. https://doi. org/10.1007/s40265-017-0777-2.

163. Ishizuka T, Matsui T, Okamoto Y, Ohta A, Shichijo M. Ramatroban (BAY u 3405): a novel dual antagonist of TXA2 receptor and CRTh2, a newly identified prostaglandin D2 receptor. Cardiovasc Drug Rev. 2004;22(2):71-90. https://doi. org/10.1111/j.1527-3466.2004.tb00132.x.

164. Gupta A, Chiang K. Prostaglandin D2 As a Mediator of Lymphopenia and a Therapeutic Target in COVID-19 Disease (June 18, 2020). Available at SSRN:https://ssrn.com/abstract $=36334$ 69. Accessed 8 Jul 2020. 


\section{Affiliations}

\section{John G. Rizk ${ }^{1}$ - Kamyar Kalantar-Zadeh ${ }^{2,3,4} \cdot$ Mandeep R. Mehra $^{5} \cdot$ Carl J. Lavie $^{6} \cdot$ Youssef Rizk $^{7}$. Donald N. Forthal ${ }^{8,9}$}

1 Edson College, Arizona State University, Phoenix, AZ, USA

2 Division of Nephrology, Hypertension and Kidney Transplantation, University of California, Irvine, School of Medicine, Irvine, CA, USA

3 Department of Epidemiology, University of California, Los Angeles, UCLA Fielding School of Public Health, Los Angeles, CA, USA

4 Tibor Rubin VA Long Beach Healthcare System, Long Beach, CA, USA

5 Brigham and Women's Hospital and Harvard Medical School, Boston, MA, USA
6 John Ochsner Heart and Vascular Institute, Ochsner Clinical School-The University of Queensland School of Medicine, New Orleans, LA, USA

7 Department of Family Medicine, American University of Beirut Medical Center, Beirut, Lebanon

8 Division of Infectious Diseases, Department of Medicine, University of California, Irvine, School of Medicine, Irvine, CA, USA

9 Department of Molecular Biology and Biochemistry, University of California, Irvine, School of Medicine, Irvine, CA, USA 